\title{
Ecological impact of coastal defence structures on sediment and mobile fauna: evaluating and forecasting consequences of unavoidable modifications of native habitats
}

\author{
Daniel Martin ${ }^{1, *}$, Fabio Bertasi ${ }^{2}$, Marina A. Colangelo ${ }^{2}$, Mindert de Vries ${ }^{3}$, Matthew \\ Frost $^{4}$, Stephen J. Hawkins ${ }^{4,5}$, Enrique Macpherson ${ }^{1}$, Paula S. Moschella ${ }^{4}$, M. Paola Satta ${ }^{1}$, \\ Richard C. Thompson ${ }^{6}$, Victor U. Ceccherelli ${ }^{2}$,

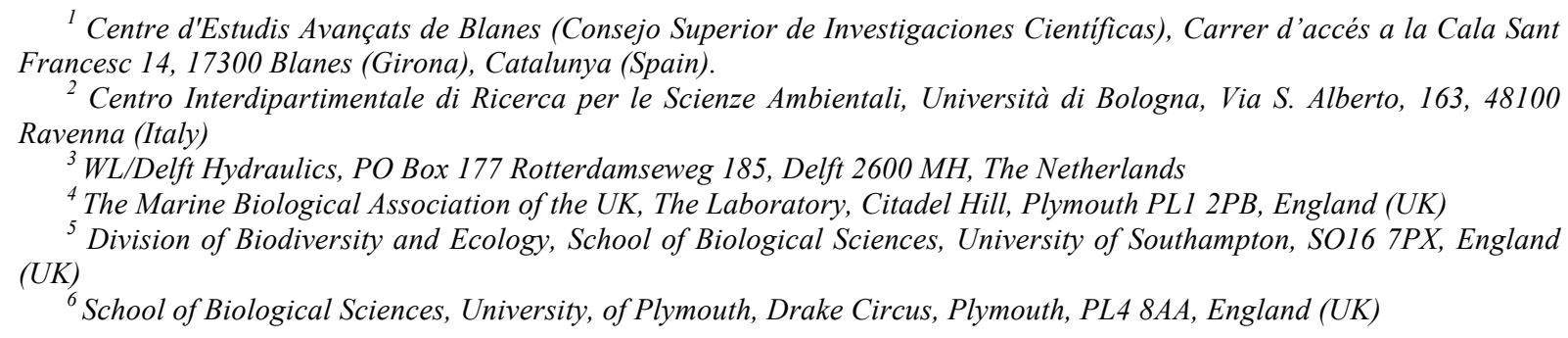

\begin{abstract}
We analyse the effects of coastal defence structures, mainly low crested (LCS), on the surrounding intertidal and subtidal infaunal assemblages and mobile fauna. The results summarise joint studies within the DELOS project in Spain (Mediterranean Sea), Italy (Adriatic Sea) and UK (English Channel and Atlantic Ocean). We demonstrate that univariate analysis did not generally identify LCS impacts, but multivariate analyses did, this being a general trend across all locations and countries. Changes in sediment and infauna seem to be inevitable and usually tend to induce negative changes, particularly on the landward side and in the presence of additional structures or after beach nourishment. The consequences of LCS construction always depend on the response of the assemblages inhabiting a given region. However, to assess the ecological importance of the induced changes and to provide additional monitoring criteria, likely indicator species should be taken into account. The presence of species either coming from the new hard bottoms or associated to physical disturbances is viewed as a negative impact, while the potential nursery role of LCS is a positive one. The combined use of monitoring and forecast models allows to identify these impacts and may play a relevant role in mitigation protocols. Finally, our work supports the feasibility of introducing design criteria tending to facilitate a positive evolution of the assemblages surrounding the structures once the changes due to the presence of the LCS are completed and the new situation tends to become more stable
\end{abstract}

Keywords: Environmental impact; coastal defence structures; low crested; sediments; infauna; mobile fauna; biotope forecasting.

\footnotetext{
* Corresponding author. Tel.: 349723500 11; fax: 34972337806.

E-Mail address: dani@ceab.csic.es (D. Martin)
} 


\section{Introduction}

Any structure placed in a coastal environment modifies the wave regime and depositional processes. These changes will impact the species composition, abundance and trophic structure of the invertebrate assemblages inhabiting marine sedimentary environments (softbottom benthos), particularly those living within the superficial layer of sediments (infauna). These organisms are operationally classified as microbenthos $(<38 \mu \mathrm{m})$, meiobenthos (from $38 \mu \mathrm{m}$ to $1000 \mu \mathrm{m})$ and macrobenthos $(>1000 \mu \mathrm{m})$ according to the sieve mesh size used for extraction from sediment cores or grabs. The macrobenthos, composed mainly of molluscs (shellfish, snails), polychaetes (bristle worms), crustaceans (amphipods, shrimps, crabs) and echinoderms (sea cucumbers, brittle stars) (Gray, 1981), is the infaunal comonent most widely used in environmental impact studies (Pearson and Rosenberg, 1978; Pocklington and Wells, 1992; Paiva, 2001). Macrobenthic organisms are useful for impact studies as they are relatively non-mobile, and therefore respond to local effects. Living organisms integrate relatively long-time environmental events at a particular place and their quantitative sampling is relatively easy (e.g. Holme and McIntyre, 1971).

Changes in benthic communities may be assessed by using parameters such as species composition, abundance and biomass. Alternatively, trophic-functional groupings can be used (Probert, 1984; Paiva, 1993; Pinedo et al., 1997; Martin et al., 2000). Trophic structure of a species assemblage may remain constant even if the taxonomic composition varies (Heatwole and Levins, 1972). Thus the collective response of trophic groups to environmental changes is likely to be more indicative of the reaction of the whole community than individual species (Begon et al., 1996).

Hydrodynamics has been considered as the ultimate factor not only affecting the spatial distribution of different sediment types but also the associated benthic organisms (Nowell, 1983; Jumars and Nowell, 1984; Nowell and Jumars, 1984; Butman, 1987a, 1987b; Miller and Sternberg, 1988). The consequences may vary for different marine environments however, depending on both morphodynamic shore types and the local benthic assemblages. Shore systems can be classified according to a continuum from reflective to dissipative states on the basis of their dynamic (i.e. prevailing winds, waves, currents, tidal regimes) and morphological characteristics (i.e. coast orientation, shelf extent, bathymetry) (Short and Wright, 1983). This shore morphodynamic gradient seems to determine some characteristics of the benthic macrofauna, such as the well-known relationship existing between a trend in decreasing macroinvertebrate species richness along a gradient from dissipative to reflective 
shore conditions (Brazeiro, 2001). Thus, any artificial coastal defence structure, which includes Low Crested Structures (LCS) built to prevent coastline erosion, will impact softbottom benthic assemblages by altering both hydrodynamic and sedimentary characteristics of the surrounding habitats.

Shallow near-shore systems are open and dynamic. The presence of intertidal flats and very shallow subtidal areas intensifies the exchange of matter and energy between well-mixed water columns and the sediments. In turn, the sedimentary organic content may co-vary with primary production (both by phytoplankton and phytobenthos), grain size, pore-water chemistry and microbial and infaunal abundance and composition. All these parameters are influenced by the near-bed flow regime (Snelgrove and Butman, 1994), as well as the advective processes transporting organic particles and supplying larvae (Rosenberg, 1995). Assemblages in near-shore ecosystems are therefore determined by both hydrodynamics and sediment-transport processes (Nowell, 1983; Jumars and Nowell, 1984; Nowell and Jumars, 1984; Butman, 1987a, 1987b; Miller and Sternberg, 1988). Thus, anything which may modify these processes such as the presence of LCS will inevitably have an affect on the ecology.

There has been much controversy about the effect of the placement of artificial structures on the seabed on the enhancement of mobile fauna (mainly fish). In principle, these artificial structures act to aggregate fish (Sanchez-Jerez et al., 2002; Duffy-Anderson et al., 2003), providing sources of food (e.g. macroinfaunal organisms), refuges from predators and suitable sites for reproduction and recruitment. The debate is whether these artificial structures enhance the fish community only locally or if the effect has positive consequences at a broader spatial scale, for example for regional fisheries (Sanchez-Jerez et al., 2002; DuffyAnderson et al., 2003). Most of this controversy, however, deals with artificial reefs, which are usually located at greater depths and far from the shoreline compared with the typical setting for coastal defence structures such as the LCS.

Our research was planned as an integrated European wide study to identify, describe and quantify the impacts of the LCS on the biodiversity and functioning of soft-bottom macroinvertebrate communities at a range of spatial (local, regional and European) scales and in relation to different environmental conditions (micro- and macro-tidal ranges, wave action, surrounding habitats and different LCS typologies). We have investigated the impact of LCS on soft-bottom assemblages by comparing their composition, structure (i.e. abundance and biomass) and trophic-functional groups around (landward and seaward sides) different types of LCS with control areas without structures. At a local scale, the potential direct and indirect effects of LCS on the enhancement of mobile fauna (mainly fish and crustaceans) have also 
been investigated by comparing their composition and abundance around the LCS with controls. Moreover, the effects of the accumulation of drifting algae around LCS systems on fish settlement were also investigated. In all cases, the observed changes were related to selected hydrodynamic and sedimentary variables (i.e. tidal regime, bathymetry, grain size, organic matter content, chlorophyll- $a$ content) and LCS characteristics.

A model attempting to forecast the potential impacts of adding LCS to an area was developped. The assumption was that if a model could be developed that forecasts physical changes to the environment in terms of altering current velocities and sediment composition, then it might also be possible to forecast resulting changes in the local ecology. This approach appeared particularly suitable for sandy beaches, where the macrofaunal communities are controlled almost entirely by physical processes (McArdle and McLachlan, 1992) rather than by biological interactions (McLachlan et al., 1995). Thus, in order to develop a suitable forecasting tool for assessing potential impacts of LCS, two stages were considered. The first was an accurate forecast of the physical changes that might occur as a result of the presence of LCS by using a model system describing hydrodynamics, wave action and sediment transport for a given study area. The second stage involved a rule-based expert system linking the physical changes to effects on the biological community, which can be exploited in order to forecast changes in the latter as a result of changes in the former. Once developed, the forecasting tool was tested on the English Channel at Elmer (see below) to assess the model's accuracy in a) predicting the biological assemblages occurring in a 'natural' situation (i.e. without LCS present) and b) predicting biological assemblages in an 'impacted' situation (i.e with LCS present).

\section{Study sites}

\subsection{Altafulla (Catalunya, Spain).}

Altafulla is a typical Mediterranean beach with an average slope of about $1.7 \%$ and very fine sand (mean grain size of about $0.12 \mathrm{~mm}$ ). It is a storm-wave dominated beach, with a micro-tidal range of approximately $0.2 \mathrm{~m}$ and prevailing winds from the east (winter) and south-east (summer). Long-shore sediment transport dominates coastal processes in this area.

The LCS in Altafulla (Fig. 1A) was built to protect the sand added in front of a small rocky promontory and to transform the two previously separated northern and southern coves 
into a single large beach. The LCS is a simple, single structure, parallel to the coastline. It is $116 \mathrm{~m}$ long, $21 \mathrm{~m}$ wide at its base and $5 \mathrm{~m}$ wide at the crest, with a freeboard of $0.5 \mathrm{~m}$ width and approximately $5 \mathrm{~m}$ in total height. It can be overtopped by waves of less than $1 \mathrm{~m}$ in height. The distance to the coast is about $180 \mathrm{~m}$ but at the centre of the structure there is a well-developed tombolo. The structure is highly porous with a concrete base, internal limestone blocks, and granite facing.

\subsection{Cubelles (Catalunya, Spain)}

Cubelles is close to Altafulla, with similar climate and tidal regimes. The LCS studied is part of a series of structures extending along $3 \mathrm{Km}$ of coast. The longest structure, placed in the middle of the defence scheme, was built to protect the inlet and outlet seawater flows coming from the thermal power station of Cubelles. The other structures, including the one selected for study, were built to protect the beaches following beach nourishment.

The LCS studied (Fig. 1B) consists of three breakwaters parallel to the coastline and two lateral groins (the southern one semi-submerged). All three breakwaters have a welldeveloped tombolo. Each breakwater measures $6 \mathrm{~m}$ wide and $130 \mathrm{~m} \mathrm{long}$, is approximately 5.5 to $5.8 \mathrm{~m}$ in total height. and can be overtopped by waves of less than $1 \mathrm{~m}$ in height. They are separated from each other and from the lateral groynes by $175 \mathrm{~m}$ gaps, and the maximum distance to the high water mark is $230 \mathrm{~m}$ (although this is highly variable due to differences in sand deposition). The structures are built with materials similar to those in Altafulla.

\subsection{Calonge (Costa Brava, Catalunya, Spain)}

The LCS system was built in 1981 (and then rebuilt in 1986 and 1998) to protect a sandy beach located between the Palamós harbour to the north and a southern rocky coast. The system consists of three structures parallel to the coastline, each of them showing a welldeveloped tombolo. The breakwaters measure $6 \mathrm{~m}$ wide and $170 \mathrm{~m}$ long, being approximately $6 \mathrm{~m}$ in total height. They are separated from each other by $100 \mathrm{~m}$ gaps (Fig. 1C). The structures are built using materials similar to those in Altafulla and Cubelles.

Weather conditions are characterized by typical spring and autumn storms [significant wave height values $>1 \mathrm{~m}$ and high diurnal wind speeds (mean ranging between 1.39 and 1.64 $\left.\left.\mathrm{m} \cdot \mathrm{s}^{-1}\right)\right]$. 


\subsection{Lido di Dante (Emilia-Romagna, Italy)}

Lido di Dante is on the Adriatic coast, $7 \mathrm{~km}$ from Ravenna (Italy) between the Fiumi Uniti and Bevano river mouths. The coastline consists of a flat dissipative sandy beach, with a wide surf zone, which isexposed to wind and wave action mainly from the southeast (summer) and northeast (winter). The seabed has a gentle slope of about $6 \mathrm{~m} \mathrm{Km}^{-1}$ and the maximum tidal range is $0.90 \mathrm{~m}$.

The LCS of Lido di Dante (Fig. 1D), constructed in 1995, measures $770 \mathrm{~m}$ in total length, with a central gap of $30 \mathrm{~m}$. It is $24 \mathrm{~m}$ wide at its base and $5 \mathrm{~m}$ at the crest, which is $0.5 \mathrm{~m}$ below the MSL. The LCS, built with limestone quarry rocks, runs almost parallel to the coastline for $180 \mathrm{~m}$ from the shore on the $3.5 \mathrm{~m}$ depth isobath. The system has three additional groynes, which are $300 \mathrm{~m}$ apart. The northern and southern groynes have a submerged section connecting their heads to the LCS. This design gives rise to an area almost completely confined from the surrounding seabed.

\subsection{Elmer (West Sussex, UK).}

The Elmer LCS system is predominantly exposed to south-westerly winds in West Sussex (south of England). The mean tidal range is $6.3 \mathrm{~m}$. The beach consists of a shingle bank high on the shore and medium to fine sand lower down. Longshore sediment drift runs from west to east. The coastline prior to the construction of the defence scheme was subject to rapid erosion and the low-lying residential area to the landward side was often flooded due to storms or extreme spring tides.

The Elmer defence scheme was built after extreme storm events during 1989-90 caused major erosion of the shoreline and flooded properties (Fig. 1E). As a consequence 8 shoreparallel breakwaters were built between 1991 and 1993. These were designed to reduce the near shore wave energy and retain nourished shingle deposited at the top of the shore (Fig. 1E). The LCS are made of Norwegian granite and do not have a core, thus overtopping is reduced. Their crest height is approximately $6 \mathrm{~m}$ and the top is $4 \mathrm{~m}$ wide. They are located $130 \mathrm{~m}$ from the shoreline, although this distance varies slightly between structures. Most of the structures have led to a tombolo being formed on the landward side, which is therefore at a slightly higher tidal level than on the seaward side.

\subsection{King's Parade (The Wirral near Liverpool, UK).}


The King's Parade breakwaters are located on the North Wirral (England), with a macrotidal regime (10 $\mathrm{m}$ maximum range). The shore consists of fine sand flats, forming dunes and gullies. Littoral drift is predominantly in the N-E direction. The North Wirral coast is subject to erosion caused by a combination of high spring tides and exposure to large waves under stormy conditions. The lack of sediment supply from the North Welsh coast coast means that there is little replenishment to compensate for erosion.

The breakwaters were built between 1984 and 1985 and consist of pre-cast concrete T units (diodes) and armourstone blocks (Fig. 1F). This type of mixed concrete and armourstone structure is more porous than that built with natural stone. This allows the construction of a lower crest level, as a consequence of a reduced overtopping effect. The two breakwaters have a slightly different design, although they are both connected to the shore. One breakwater has a Y shape, whilst the other has a T shape. Their crest level is $4 \mathrm{~m}$ and the offshore segment of the $\mathrm{Y}$ and $\mathrm{T}$ shaped breakwaters is $240 \mathrm{~m}$ and $260 \mathrm{~m}$ long respectively. The distance of the offshore segments from the shoreline is approximately $200 \mathrm{~m}$. Due to the extensive tidal range and minimal beach slope, there are negligible differences in the tidal level between the landward and seaward side of the breakwaters.

\section{Materials and methods}

\subsection{Sedimentary and biological descriptors}

To evaluate changes in sediment characteristics and associated effects on biota, one of the initial priorities within the DELOS project was to clearly define the most relevant sedimentary and biological variables allowing description of the patterns and trends of the infauna surrounding the LCS and hence their impact. The sediment descriptors chosen were: depth of the water column, granulometry (percentages of silt/clay and coarse sand; mean and median grain size) according to the standard dry-sieved procedure (Wentworth, 1972), total organic matter content (estimated as losses by ignition, $110^{\circ} \mathrm{C}$ for $24 \mathrm{~h}$ and $450^{\circ} \mathrm{C}$ for $5 \mathrm{~h}$ ) and chlorophyll- $a$ content (considered as the functional chlorophyll corresponding to living epiphytobenthos present on the sediment surface) estimated by spectrophotometry (Lorenzen, 1967, adapted to sediment conditions by Holm-Hansen and Riemann, 1978).

Most of the descriptors used to describe the infaunal assemblages rely on the identification of organisms to the species level (whenever possible). These are: species 
richness (as number of species per sample), Shannon Index for species diversity (Shannon and Weaver, 1949) and abundance (ind. $\mathrm{m}^{-2}$ ). Trophic-functional groupings were also used, adapted from Fauchald and Jumars (1979) and Dauvin and Ibanez (1986): S, suspension feeders; SD, surface-deposit feeders; SSD, subsurface-deposit feeders; C, carnivores/herbivores. Moreover, some animals living within the benthic boundary layer may feed by using a mixed strategy (Group M), behaving as deposit or suspension feeders in response to varying boundary flow rates (Taghon et al., 1980; Levinton, 1991; Taghon and Greene, 1992).

\subsection{Faunal sampling methods and experimental designs}

The sampling required to adequately describe assemblages was assessed according to the methods described in Martin et al. (1993). Van Veen grabs of $600 \mathrm{~cm}^{2}$ (three replicates) were used in the subtidal in Italy and Spain, while PVC corers of $180 \mathrm{~cm}^{2}$ (six replicates) were used in the intertidal in the UK.

Two sampling strategies have been used. The first used a balanced hierarchical design, which allowed formal statistical comparisons using a two-way nested analysis of variance (ANOVA). The design consisted of three treatments for each selected LCS systems (King's Parade, Elmer, Lido di Dante, Cubelles and Altafulla): landward and seaward sides of the structure, as well as control or reference areas (i.e., similar habitats non-influenced by the presence of the LCS). Within each treatment, four sites were randomly selected along the structures. Then, within each site, either three (Spain and Italy) or six (UK) random replicate samples were collected. The same design was adopted to evaluate the responses of environmental descriptors, benthic infauna and mobile fauna.

The second sampling strategy assessed the extent of the area of influence of the LCS at successive distances from the structures (Fig. 2). In this case, the experimental designs were specifically adapted to the particular scheme and local hydrodynamic/ecological peculiarities of each LCS studied (Altafulla, Lido di Dante, Elmer and King's Parade).

At Altafulla, the sampling design was based on the theoretical hydrodynamic model developed by the engineer DELOS partners (Sanchez-Arcilla et al., this volume). They demonstrated that the main forces driving the dynamics of the system were concentrated on the landward of the structure. The design included three transects of three stations starting at 3-5 $\mathrm{m}$ from the structure and running toward the coastline (about $50 \mathrm{~m}$ of distance between stations), a similar transect running from the structure seaward (three stations separated $50 \mathrm{~m}$ 
each other and starting at $50 \mathrm{~m}$ from the structure) and two control transects to the north and south of the structure. This scheme overlapped with the previous sampling design to assess the local influence, so that the corresponding stations complemented the transects to complete the design.

At Lido di Dante, previous studies had shown that there were non-significant differences between control and seaward. Thus the design assessed changes with increasing distances landward as treatments and reference transects. For each treatment, two isobaths (2.5 and $1.0 \mathrm{~m}$ depth) were chosen and five sampling sites nested within the isobaths were randomly selected.

At King's Parade, the tidal range was considerably larger (10 $\mathrm{m}$ on spring tides), therefore control areas were selected at one tidal level only and at one distance from the structures. Additional sampling was carried out at increasing distances, approximately $20 \mathrm{~m}$ and $50 \mathrm{~m}$ inshore and offshore from the structures.

At Elmer, the samples were collected on the landward and seaward side of the eight structures and in control areas at increasing distances (approximately $150 \mathrm{~m}, 500 \mathrm{~m}$ and 1500 m) from the structures along the coast, eastward and westward. At each distance the control areas were chosen at two different tidal levels, corresponding to the landward and seaward side of the structures, to avoid possible confounding of effect of tidal elevation with the effects of LCS.

\subsection{Mobile fauna: survey methods and experimental design}

The LCS systems at Calonge, Cubelles and Altafulla were sampled twice a year (winter-spring and summer-autumn) during two years using a similar sampling methodology, which consist on three treatments (controls, landward and seaward faces of the LCS). Within treatments, either 6 (landward and seaward) or 12 (controls) transects were sampled. The controls (two sites) were randomly selected on natural rocky shores with environmental features similar to the LCS (e.g. depth, slope), located at several kilometres north (Cubelles and Altafulla) and south (Calonge) of the LCS systems. Underwater fish visual censuses were carried out by transects measuring $5 \times 100 \mathrm{~m}$ between the bottom and the surface (ca. $0-4 \mathrm{~m}$ depth). Blennies, gobies and other small or cryptic species were sampled separately, following the same transect scheme, in order to obtain more accurate estimates of their abundance. All transects were carried out during optimum conditions of calm weather and under high visibility conditions. About seven species of gobies, as well as species usually 
dwelling in caves or holes (e.g. Moray eels - Muraena helena, Conger eels - Conger conger, Forkbeards - Phycis phycis) may have been underestimated. Thus, they have been excluded from the analyses. Numbers of individuals were recorded on each dive.

The Elmer LCS defence scheme was sampled once a year for three years by means of a beach seine net, multimesh gill nets and crab pots to capture pelagic and benthic fish, crabs and prawns. Sampling sites were randomly located on the landward and seaward sides of the LCS. Areas located on a sandy beach (Climping) adjacent to the LCS were chosen as a reference site. Sampling was repeated at different times of the day and in relation to rising and falling tides, as it is known that tidal and diel cycles affect the abundance and composition of fish communities. For each catch, fish, crabs and prawns were identified and counted. The seaweed detritus caught in the nets was also recorded and quantified, to investigate the indirect effect of LCS on fish abundance through accumulation of drift algae around the structures.

The effect of the accumulation of drifting algae around a LCS system on the fish settlement was also investigated at Blanes (Catalan coast, NW Mediterranean). The numbers of new settlers inside drifting algae were compared to areas with the same algae attached to the rocky substratum. 36 cores $\left(400 \mathrm{~cm}^{2}\right.$ in cross-section and $5 \mathrm{~L}$ in volume each) were taken on the same day, 18 from drifting algae and 18 from attached algae. The sampling was carried out six times in 2001 and eight in 2002.

\subsection{Statistical methods}

Sediment (e.g. granulometry) and infaunal/mobile fauna descriptors (e.g. diversity) were analysed using univariate and multivariate approaches. The effect of LCS on sediment characteristics and infaunal/mobile fauna abundance (total number of individuals) and diversity (Shannon index) was formally tested by using analysis of variance (ANOVA). Two factors were considered: factor 1 (treatment) was fixed and consisted of three levels: seaward, landward and control; factor 2 (site) was random and nested in treatment, and consisted of 4 levels. Number of replicates varied between 3 and 6, depending on the system studied. A nested design was chosen to detect differences at different spatial scales and establish generality of results (Underwood, 1997). Data were tested for heterogeneity of variance using Cochran's test and where necessary appropriately transformed to allow ANOVA analyses (Underwood and Jernakoff, 1981; Underwood, 1997). Two way nested ANOVA was performed using the G-Mav ${ }^{\circledR}$ and STATISTICA ${ }^{\circledR}$ software packages. 
The structure of faunal communities was also analysed using multivariate approaches: non-metric multidimensional scaling (MDS), two-way nested analysis of similarities (ANOSIM) and principal component analyses (PCA). All multivariate analyses were performed using the PRIMER ${ }^{\circledR}$ software package (Clarke and Warwick, 1994; Clarke and Gorley, 2001).

Multispecies patterns, in terms of species composition and their relative abundance were analysed by MDS (see Clarke \& Warwick, 1994) and visualized in two-dimensional plots where a greater distance between points indicates a greater dissimilarity. The match between the similarity matrix and the MDS plot is measured by the stress value.

Significant differences of community composition between treatments (seaward, landward and controls) were identified by means of ANOSIM (Clarke, 1993). Community structure, in terms of trophic-functional group composition and their relative abundance were analysed by PCA. PCA axes are simple linear combinations of the values for each variable, easing interpretation (Chatfield and Collins, 1980; Jackson, 1993). Main distributional trends of both environmental and infaunal data were identified using isolines. Contour maps for abiotic and biotic descriptors were based on a bi-dimensional interpolation (40 rows per 63 columns grid size) using Kriging as the gridding method. Land nodes were blanked using digitised series of co-ordinates representing the shoreline profile. Contour map analyses were performed by means of the Surface Mapping System (SURFER) 6.01 (C Golden Software Inc.).

\subsection{Modelling and biotope forecasting methods}

The DELFT3D package, developed by WL / Delft Hydraulics in close cooperation with Delft University of Technology, has been used to forecast physical changes that may occur as a result of the presence of a LCS. DELFT3D is a model system consisting of a number of integrated modules, which, together, allow the simulation of hydrodynamic flow, computation of the transport of water-borne constituents such as salinity and heat, short wave generation and propagation, sediment transport and morphological changes. It enables the modelling of ecological processes and water quality parameters. At the heart of the DELFT3D modelling framework is the FLOW module, which performs the hydrodynamic computations and simultaneous (or "on-line") calculation of the transport of salinity and heat. Moreover, the FLOW module has been recently improved thanks to the addition of the on-line computation of sediment transport and morphological changes (Lesser, 2000; Lesser et al., 2002). 
To link physical changes around the LCS to the effects on its associated biota the BioMar Classification developed for the UK and Ireland (Connor et al., 1997) was used. This is a hierarchical classification designed as an aid to conservation and management, with the identification and mapping of biotopes being a primary focus. A biotope is defined as 'the habitat together with its recurring associated community of species, operating together at a particular scale'. One of the stated aims of the BioMar classification system is to provide a basis for the predicting the biological character of an area based on its physical environment (Connor et al., 1997). Thus the BioMar scheme was used to develop rules to predict changes in the biological community as a result of changes in the physical environment.

The Delft3D-sediment-online software was used to model the hydraulic conditions for two cases with a breakwater (with and without waves), and two control cases without a breakwater (with and without waves). Bathymetry, tidal range and wave data measurements from the Elmer area (courtesy of M. Collins, Southampton Oceanography Centre, SOC) were used as inputs for the model. The situations with waves (i.e. stormy weather conditions) were modelled by setting the wave height at $\mathrm{Hs}=2.5 \mathrm{~m}$. A curvilinear grid was constructed for an area of $800 \mathrm{~m}$ cross-shore and $750 \mathrm{~m}$ alongshore. The grid has a maximum resolution of $10 \mathrm{x}$ $6 \mathrm{~m}$ and consists of 5500 active cells. By interpolation of the samples a bathymetric chart was generated. Granulometric data for the area were also provided by SOC.

The input of the above data led to an output of raw data values being obtained for bed shear stress and current velocities for each cell. All the continuous values produced by the model then had to be converted to class values to match the BioMar physical parameters. BioMar wave exposure categories were derived from bed shear stress values and BioMar tidal stream categories were derived from values for current velocity. BioMar height zones were determined from the bathymetric and tidal range data. Other categories used as part of the BioMar classification (salinity and substratum type) were input directly from measurements rather than produced as a result of the model. The result of this coupling was a set of BioMar class values being forecasted for each of the 5500 cells.

To test forecasting ability, an accurate map of biotopes in the field was produced for comparison with those predicted by the model at Elmer in the summer of 2003. The area mapped was between breakwaters three and four, as this corresponded to the area where the physical data used to produce the model output was taken by SOC. Biotopes were mapped using GPS co-ordinates to mark the boundaries and infaunal cores were also collected to confirm the biotope designations. In order to represent a reference state (i.e. without 
breakwaters present), data from areas either side (and beyond the influence) of the breakwaters were used.

A subsequent Delft3D post-processing module was then applied that selected the biotopes that could occur within the class values for each cell. If one of the biotopes selected by the model for a particular cell matched the field biotope, then this was recorded as a 'hit'. This enabled the accuracy of the model (defined as percentage of hits) to be evaluated for each situation in a straightforward fashion.

\section{Results}

4.1 Effects of LCS on the surrounding soft bottoms and the associated macrofaunal assemblages

\subsubsection{Analyses based on a balanced hierarchical sampling design}

The environmental variables did not differ significantly between treatments in almost all locations investigated, except for King's Parade defence scheme, where there was a significant increase in the chlorophyll $a$ content and silt/clay percentage in the sediment on the landward side of the structures (Table 1). However, some patterns can be identified. The chlorophyll $a$ content to the seaward side was slightly higher than to the landward side and in controls at Elmer, whilst it was higher to the landward at Lido di Dante. Probably the respective hydrodynamic regimes are responsible for this difference. Indeed, the lack of a clear response of the environmental variables examined to the presence of the LCS was probably due to the high within treatment variability (Table 1).

The univariate approach in analysing the structure of the macrofaunal assemblages surrounding the LCS also revealed very high within-treatment variability (Table 2): this prevented the detection of differences in number of species except at Lido di Dante. At this site, the number of species was always significantly higher to landward and did not differ between seaward and controls.

The Shannon diversity index did not vary around the Altafulla, Cubelles and Elmer LCS. Conversely, there was a significant influence of the structures in King's Parade and Lido di Dante (Table 2), where post-hoc tests revealed that diversity was lower on the landward side but similar between landward and controls in the former. In contrast, diversity was significantly higher on the landward side than at the two other treatments in the latter. 
The presence of LCS induced an overall increase in diversity in all the studied areas. Differences among communities in the three treatments were due both to the change in the dominance relationships among species and the occurrence of some species which occurred exclusively on the seaward and landward of the structure. Several species are typical of rocky bottoms (e. g. the bivalve Mytilus, the cnidarian Paranemonia cinerea, the cirripede Balanus sp., the amphipod Caprella sp., the ascidian Microcosmus sp., the decapod crabs Portunus sp. or Liocarcinus sp. (i.e. in Spain and the UK). Salt marsh or lagoonal species such as the bivalves Musculista senhousia and Cerastoderma glaucum, the polychaetes Neanthes succinea and Hediste diversicolor and the chironomid larvae occurred on the landward at Lido di Dante.

While the absolute number of species differed between locations, consistent patterns were observed in the percentages of species exclusive to the landward and seaward side of the LCS. All of them ranged between $25 \%$ and $35 \%$ (Fig. 3), with the exception of the seaward sides in Altafulla and Lido di Dante (less than 20\%). In contrast, at least $58 \%$ of species found in Lido di Dante were exclusive to the landward side (Fig. 3).

The multivariate analysis also revealed that the most marked influence of the LCS occurred to landward, where samples tended to be grouped separately from an often wellidentifiable seaward/control cluster in the MDS plots (Fig. 4). ANOSIM tests revealed that differences were significant both for Site and Treatment factors (Table 3). The pairwise comparisons always showed significant differences both between landward and controls and between seaward and landward in all locations considered (Table 3), while the only significant differences between seaward and control occurred in Altafulla and Cubelles.

\subsubsection{Impacts at increasing distances on sediment and associated macrofaunal assemblages}

Mapping the patterns of sediment and organism distribution at increasing distances from the LCS in Altafulla showed clear differences with respect to control transects (Fig. 5A, 5B). On the control transects there was a more or less progressive increase of fine sediment content and macrobenthos abundance from shallow to deep waters, while, close to the structure, fine sediments tended to be less abundant than in the controls at the corresponding depths. There is a clear reduction at the southern side of the hemi-tombolo and a relative accumulation to the north (Fig. 5A). In turn, macrobenthic densities showed a greater variability around the LCS than along the control transects, with the abundance being higher at the southern side of the hemi-tombolo that on the northern side (Fig. 5B). Also, some species (such as the polychaete 
Capitella capitata) showed a typical response to the changes induced by the LCS. Their most abundant populations in Altafulla and Cubelles occurred mainly on the landward side, where they showed an enormous relative increase with respect to the control (Fig. 5C). C. capitata was mainly found in the fine sediments in the southern areas on the landward side of the Altafulla LCS.

In Lido di Dante the influence of LCS extended as far as the shoreline of the protected area. Marked differences of both abiotic and biotic descriptors were found between landward and controls also near the shoreline, at the $1.0 \mathrm{~m}$ isobath. The analysis of total organic matter and silt/clay showed significantly higher average values on the landward side. Marked differences occurred also in the structure of macrofaunal communities. A significant increase in the number of species occurred to landward, with respect to the control, at $1 \mathrm{~m}$ depth. Moreover, the MDS plot (Fig. 6A) showed a gradual change from $1 \mathrm{~m}$ control treatment to $2.5 \mathrm{~m}$ landward one, passing through $1 \mathrm{~m}$ landward and $2.5 \mathrm{~m}$ control treatment. This result outlined how composition of macrobenthic assemblages tended to change step by step in response to near-bed hydrodynamic conditions induced by the LCS. A similar response was observed for the polychaete Capitella capitata as for the Spanish LCS. The pattern shown above by the MDS analysis (Fig. 6A) is mirrored by changes in densities of C. capitata. This surface deposit feeder showed significantly higher abundance on landward than in control $(F$ $=11.25 ; p<0.01$ ) where it was detected only occasionally (less than 5 individuals per $\mathrm{m}^{2}$, on average).

At Elmer, the presence of the LCS scheme did not significantly affect the sediment characteristics of the beach, either in close proximity to the structures or at increasing distances from them (eastward and westward). The mean percentage of silt/clay and organic matter in the sediment was, however, slightly higher on the landward side of the structures than in any other areas sampled (seaward and control). Differences soon disappeared, however, at increasing distances from the LCS. The increase in tidal elevation that can occur on the landward side of the structures as a consequence of tombolo or salient formation does not seem to influence the sediment characteristics. Very similar values of organic matter and grain size were observed in control areas located at the same tidal height as the landward and seaward side. Only chlorophyll- $a$ showed slightly higher concentrations in areas at lower tidal level, including the seaward side.

In contrast, LCS significantly influenced the abundance and composition of the infaunal communities. Infaunal assemblages on the landward areas differed from those on the seaward side and all control areas (Fig. 6B). The area of influence of LCS, however, does not 
extend further than the landward side of the structures. Sediment infauna did not differ between controls, independently of their distance from the LCS scheme and the tidal level at which they were located.

At King's Parade, more marked modifications were observed in the sediment characteristics around the LCS, although differences between locations were still not significant. The percentage of silt/clay was higher on the landward than on the seaward side of the structure and control areas. The sediment on the landward side of the structures becomes much finer, muddier and anoxic because of the reduced hydrodynamics, thus forming a highly modified habitat. These conditions, however, rapidly disappear at increasing inshore and offshore distances from the LCS. Also, the amount of organic matter and chlorophyll- $a$ in proximity of the structure differed from all the other areas. The variables examined, although varying considerably between $2 \mathrm{~m}, 20 \mathrm{~m}$ and $50 \mathrm{~m}$ inshore and offshore from the structures, did not follow a consistent pattern.

Similarly to the abiotic features, a sharp difference in the infaunal assemblages between the landward and the seaward side was observed on the LCS investigated at King's Parade (Fig. 6C). The largest difference in the structure of infaunal assemblages was observed between areas on the landward side of the structures and controls. A typical response to the presence of the LCS was shown by the amphipod Corophium, which occurred in extremely high numbers (about 1300 individuals $\mathrm{m}^{2}$ ) on the landward side of LCS but was extremely rare on the seaward side and absent from the control areas. No significant modifications occurred in the communities sampled at increasing inshore distances $(20 \mathrm{~m}, 50 \mathrm{~m})$ from the structure, showing great similarity with the infauna of the seaward side and control areas. Infaunal assemblages sampled at increasing offshore distances $(20 \mathrm{~m}, 50 \mathrm{~m})$ from the structure differed highly from all other locations.

\subsubsection{Responses of trophic groups}

In Cubelles and Altafulla the percentage composition of infaunal trophic groups was similar. Both locations were dominated by the surface deposit-feeders (SD) group $(70 \%$ on average), followed by the carnivores (C) group (16\% on average), while the subsurface deposit-feeders (SSD) group accounted for 2\% (Cubelles) and 13\% (Altafulla) (Fig. 7). The suspension feeding (S) and mixed feeding (M) organisms were clearly less important (Fig. 7). Despite a significant reduction in densities of all organisms observed on the landward side in Cubelles (especially for the SD group, $F=8.24$; $<<0.01$ ), the percentage composition of 
trophic groups did not changed significantly between the treatments and the control. A similar result was obtained in Altafulla. In Cubelles the SD group showed a minor increase (+9\%) on the seaward, while in Altafulla the SSD group slightly decreased (-9\%) on the landward and the SD group tended to decrease $(-18 \%)$ on the seaward.

At Lido di Dante the control community showed a peculiar trophic structure, being almost completely dominated by the S group (94\%), followed by the SD group (4\%) (Fig. 7). On the landward, the S group decreased significantly $(F=37.73 ; p<0.001)$ due to the lower abundance of Lentidium mediterraneum. Simultaneously, all other trophic groups increased their relative abundances: $+21 \%$ for $\operatorname{SD}(F=15.39$; $p<0.01),+15 \%$ for $\operatorname{SSD}(F=48.04 ; p<$ $0.001)$ and $+13 \%$ for $\mathrm{M}(F=62.12 ; p<0.001)$. No significant changes were found on the seaward side in comparison with the control.

At Elmer (UK), the trophic structure of the control assemblage was dominated by the SD group (91\%), followed by the C (6\%) and SSD (3\%) groups. The S group was totally absent. No significant differences were found among treatments (Fig. 7), despite a small increase of the M group (+9\%) occurring on the landward side. The control assemblage at King's Parade was characterized by the SD (57\%) and C (34\%) groups, followed by the M, SSD and S groups $(6 \%, 2 \%$ and $1 \%$, respectively). On the landward side, the S group was absent, while the $\mathrm{M}$ group showed a significant increase of $41 \%(F=10.83 ; p<0.01)$ in comparison to the control. The SD group showed significant changes $(F=28.12 ; p<0.001)$ in the treatments, with a decrease $(-41 \%)$ to landward and an increase (+21\%) to seaward (Fig. 7).

\subsection{Infaunal species versus trophic groups}

\subsubsection{Geographical scale: Italy/Spain/UK}

The MDS based on the species composition of the benthic assemblages in Spain, Italy and the UK showed that the samples were grouped into three markedly distinct clusters according to their geographical locations reflecting biogeographic differences in species pools (Fig. 8A). Community structure analysis performed on the basis of trophic categories by means of a PCA ordination revealed significant patterns. On the first axis $(60.6 \%$ of the total variance), the PCA plot outlined a decrease (from left to right) of the M and SSD feeders whilst the second axis (18.2\% of the total variance) reflected the increase (from bottom to top) of the SD group (Fig. 8B). Accordingly, the analysis revealed a gradient of variability in the trophic-functional structure of the assemblages of the three countries. In Italy, the 
assemblages were characterized by the M and SSD feeders, whilst in the UK the SD feeders were much more abundant. Spanish samples (especially in controls) were clustered approximately around the centre of the plot, indicating a rather homogeneous distribution of the abundance of the trophic groups. Both in Spain and Italy, samples taken from the landward were well separated from their respective control points. They were, however, placed in opposite directions indicating that they were dominated by different trophic groups (Fig. 8B).

\subsubsection{Regional scale: Spain/UK}

The MDS plot based on abundances around the Spanish LCS (Fig. 8C) showed two main clusters corresponding to Cubelles and Altafulla. Then, within each location, the points were separated according to the treatments (control and landward), with a sharper separation within Cubelles. In turn, the analysis of trophic groups by PCA showed on the first axis $(51.1 \%$ of the total variance) decreasing values (from left to right) of the M, SSD and S groups, and, on the second axis $(21.2 \%$ of the total variance), increasing values (from bottom to top) of the SD group (Fig. 8D).

The samples from the two UK localities, Elmer and King's Parade, were clearly separated in the MDS plot (Fig. 8E). The PCA based on trophic groups for the two UK locations showed on the first axis (40.6\% of the total variance) decreasing values of $\mathrm{C}$ and $\mathrm{M}$ groups and increasing values of SD. The second axis $(21.7 \%$ of the total variance) represented decreasing values of SSD group (Fig. 8F).

\subsection{Biotope forecasting}

A total of six biotopes were recorded and mapped at Elmer during a field survey (Fig. 9A). One of them (Barren Littoral Shingle) was not used for comparison with the model, as, per definition, the model only predicted biotopes for the wetted tidal part of the shore.

The classifications needed to link physical parameters to biotope occurrence were calibrated to the field data. The predictive accuracy of the model changed between a situation with and without wave exposure. A maximum accuracy rate, of the biotope distribution that had been mapped was attained of 69\% (Fig. 9B) for the scenario of a breakwater with waves.

The hierarchical nature of the BioMar classification means that the model can also be used to predict biotope complexes, the next level up in the hierarchy. However, as the five 
field biotopes used in the model only combined to four biotope complexes, the accuracy rate of biotope complex prediction was only slightly increased, to $77 \%$ for the situation with a breakwater and with waves. The reference situation without a breakwater showed a better model performance for both biotope and biotope complexes analysis. Strikingly, performance without wave exposure was better in this case than the result with inclusion of wave exposure. Due to the lack of field data on waves for the reference situation, model performance cannot be checked. These contradictory results need elaboration in future studies.

\subsection{Mobile fauna}

Results from Spain and the UK showed that the fish assemblages and mobile fauna around the LCS consist of species both from sedimentary and rocky bottoms. Several species observed around the structures are of commercial importance in both countries. These included seabass (Dicentrarchus labrax), banded and white seabream (Diplodus spp.), red mullet (Mullus surmuletus), grey mullet (Mugil spp.), thick-lipped grey mullet (Chelon labrosus), golden grey mullet (Liza aurata), common sole (Solea solea) and plaice (Pleuronectes platessa).

Differences in abundance and composition of fish between treatments around LCS (seaward, landward) were evident only for some species, such as Diplodus spp. in Spain and Dicentrarchus labrax in the UK. These differences probably depend on the more sheltered habitat provided by the landward side.. LCS also seem to provide habitats that appear to be particularly suitable for new settlers, juvenile fish and other mobile fauna (Fig. 10A). They therefore probably enhance the settlement of fish and crustaceans in the surrounding waters, especially in the presence of accumulations of drifting algae. In particular, LCS represent a nursery ground for the juveniles of commercially important species, such as Diplodus spp. in Spain and Dicentrarchus labrax in UK.

In the UK, the abundance and composition of fish around the LCS varied in time, in relation to the tidal and daily cycle, although there were not consistent patterns . For example, in the second year of the DELOS project the highest abundance of sea bass was recorded on the landward side, whilst in the third year this species was more abundant in the gap and on the seaward side. Despite this temporal variation, however, it was observed that the abundance of fish was consistently higher around the LCS than in the control area.

The number of fish species recorded in Altafulla and Cubelles LCS were clearly smaller (19) than in Calonge (>30) (Fig. 10B). There were no significant differences among LCS 
systems and their respective controls. The low diversity in Altafulla was attributable to the environmental conditions of the LCS, situated in an open area, surrounded by large beaches and with an important abrasion effect of the waves, clearly higher than in the other two systems. The abrasion, however, was important in the three systems and had a negative effect in the abundance of branched algae, where many small fishes were found. These algae also were used by adults in reproductive (nesting) activities. As a consequence, numerous species could not settle or reproduce in these LCS. Significant differences were also found between landward and seaward sides of LCS, with settlement mostly occurring on the landward side. Nevertheless, the structure provided an artificial habitat for the settlement of some species, due to the preference of the settlers of some common species [Diplodus sargus (summer season) and D. vulgaris (winter season)] for protected zones (landward). These settlers were always absent from those coastal areas without protected areas from the dominant winds. Other common species that settle on the seaward side of LCS (e.g. Oblada melanura, Thalassoma pavo, Chromis chromis) did not show this difference. The populations of most fish species consisted of small sizes (usually juveniles or 0-2 years old).

During the surveys carried out amongst drifting algal accumulations 7 fish and 23 decapod species were observed. The results of ANOVA analysis indicated that the juvenile fish community of the drifting algae (number, abundance and diversity) was not significantly different to the community found in the attached algae ( $p>0.10$ in all cases). However, the decapod community in the attached algae was more diverse and abundant than the community living in the drifting algae $(F=120.54, p<0.01)$. Conversely, the settlement intensity for several fish (Apletodon spp, Clinitrachus argentatus, Spondyliosoma cantharus ) and decapod (Palaemon xiphias) species was significantly higher in the drifting algae than in the attached algae. Drifting accumulations of seagrass (i.e. Posidonia oceanica) leaves, however, did not show any traces of settlement of both decapod crustaceans and fish juveniles at all studies sites.

\section{Discussion}

This paper is an attempt to synthesise the main results obtained through joint research carried out in Spain (NW Mediterranean Sea), Italy (Adriatic Sea) and UK (English Channel and Atlantic Irish Sea) within the framework of the DELOS project. Many of the results obtained have been consistent. This is despite the studies being made in very different coastal 
systems: different seas, different tidal range, different wave and current regimes and hence, different types of beaches). This strengthens the findings concerning the effects of LCS on surrounding deposit dwelling assemblages and motile fauna and will help with the formulation of advice that can be incorporated into LCS design guidelines. These guidelines can eventually be applied to the management of different coastal systems in Europe.

\subsection{Impacts on soft bottoms and associated infaunal assemblages}

Shallow water assemblages are highly disturbed due to the action of waves and currents modifying sediment location and composition. Most shallow water assemblages, especially on wave exposed beaches are hence driven by physical factors (Sanders, 1969; Short and Wright, 1983; McArdle and McLachlan, 1992; McLachlan et al., 1995). The biological interactions typical of rocky substrate are much less common. The sediment regime also determines the trophic status of these assemblages. For instance, fine organically rich muds tend to contain more burrowing deposit feeders whereas coarser sediments usually harbour more mobile animals and suspension feeders.

Our first attempt to approach the problem, a balanced hierarchical sampling design with univariate analysis, did not demonstrate major effects of LCS on habitat complexity based on both sediment and infaunal assemblage descriptors except for functional and structural descriptors (i.e., diversity, trophic-functional groups). These pointed out marked differences between the assemblages surrounding the LCS and between them and control assemblages, independently of the tidal range. In terms of assemblage structure and functioning, our results suggest the existence of patchiness at a smaller scale than the selected treatments due to the tendency of the LCS to create a mosaic of habitats. This likely being the reason preventing the detection of significant impacts in the univariate analyses.

Conversely, multivariate analyses (such as MDS, PCA or ANOSIM) were always able to show differences among treatments, confirming the few patterns revealed under the univariate approach. Community-level differences between seaward and landward and between assemblages associated to LCS and controls were highlighted, with major dissimilarities always occurring between the landward side and controls. Regional differences (i.e. Spain vs. Italy vs. UK), also evident in the MDS (Fig. 8A), were only a reflection of the different species pool. The community structure analysis (PCA based on trophic-functional groups) allowed comparison of common effects, revealed a structural gradient of variability and 
pointed out the existence of localised responses of the trophic groups to the presence of the LCS in the three different geographic locations.

The analysis of trophic-functional structure also revealed regional differences at small (i.e., $20 \mathrm{~km}$ in Spain) and large scales (i.e., $1000 \mathrm{~km}$ in UK). The results in Spain seem to indicate that, despite having a similar species pool, benthic assemblages around the two LCS systems clearly differ in their trophic structure, suggesting that different processes may be involved in structuring soft bottom infauna despite the short distance between them. The close proximity of these two LCS meant large differences in the environmental dynamics were not expected. Therefore, the differences in trophic structure are a better indicator of different levels of interaction between the LCS and their respective (similar) environmental conditions caused by the different designs of the structures. Nevertheless, by comparing the MDS (based on species) and the PCA (based on trophic groups) plots, it may be seen that the two Spanish locations were more closely related in terms of trophic-functional structure than in terms of species composition (Figs. 8C, 8D). On the contrary UK locations were still clearly separated on the basis of trophic groups, this being more likely due to the different energy and wave climate of the beach, tidal range and species recruitment regimes that to the distance itself. Moreover, King's Parade defence scheme is placed at the mouth of the polluted River Mersey, which has a marked influence on the sediment dynamics and organic load and, thus, on the infaunal structure and functioning.

In general, a detectable impact by LCS on surrounding habitat occurs notwithstanding the different geographical location and particular structures investigated. Considering the whole infaunal assemblages (i.e. species present in controls, as well as around the structure), the presence of LCS induced an overall increase in diversity at all the studied areas. This qualitative increase in species richness relied on species exclusively present either on the landward side or on the landward side. In some cases, however, these species may either be typical of hard-substrata, (which occurred in the sediments having been washed off or moved away from the structures) or typical of lagoon and salt marsh habitats (which are able to colonize the calmer landward area due to the proximity of the estuarine or salt marsh habitats).

The possible presence of indicator species, such as the polychaete Capitella capitata or the amphipod Corophium spp., may also provide additional criteria to monitor the impacts of the LCS. Although C. capitata is a complex of sibling species (Grassle and Grassle, 1976), the ecological traits of most species involved are similar (Pearson and Rosenberg, 1978) and the presence of populations of these species represents an index to evaluate the disturbance 
impact on the communities around the LCS, particularly in relation to organically enrichment. In fact, at the Spanish and Italian sites, $C$. capitata was much more abundant on the landward areas, which are protected from water movements both by the structure itself and the by a hemi-tombolo (Spain) or lateral groynes (Italy). This could be a symptom of critical conditions that may easily shift to perturbed ones if water circulation is insufficient. In turn, Corophium spp. typically form semi permanent burrows in fine but also muddy areas, where conditions are particularly stable and water movement is strong (Connor et al., 2003). Accordingly, this amphipod was much more abundant on the landward side of LCS at King's Parade but was extremely rare on the seaward side and absent from the control areas. This emphasises the efficacy of this species as a good indicator of modified conditions in the sediments.

The degree of exposure and the hydrodynamic regime at the landward side, as well as the influence of the LCS on this regime, seems to be among the key features influencing the diversity of the soft bottom and mobile fauna assemblages around the LCS. However, this was seldom revealed by the balanced hierarchical sampling design, chiefly because of the patchy distribution of both the environmental variables and the biological descriptors. Therefore, we undertook a second analytical approach, based on designs including samples collected at successive distances from LCS. The respective designs were always planned according to the particular geographical/environmental characteristics of each target site. In general, however, they were able to produce an integrated picture of the systems under study, that could be linked (easily) both to the trends showed by the environmental factors and to dynamic models in order to assess the influence of water movements and sediment dynamics on the soft-bottom assemblages.

Our results pointed out that, when gradients occurred (e.g. in Altafulla), the effects of the LCS became soon undetectable, this stressing the limited area of influence of the impact generated by the LCS, independently of the particular environmental conditions and tidal regimes. The presence of LCS tends to cause an accumulation of sediments (silty and rich in organic matter), mainly on the landward side of the structures, due to modifications of the current patterns usually linked to a reduction in hydrodynamics. In Altafulla (atidal shore), where the LCS induced the formation of a hemi-tombolo (Sanchez-Arcilla et al., this volume), the accumulation of fine sediments on the landward side tends to be excessive, thus causing a significant reduction in the abundance of benthic invertebrates. The observed gradients, however, stress the limited area of influence of the impact, as the effects of the LCS became soon undetectable. Conversely, higher contents of fine sediment were positively 
correlated to infaunal abundances along the control transects, as usually occurs in biologically controlled environments (Sanders, 1969). At Lido di Dante (microtidal shore), the reduction of hydrodynamic stress on the landward side was more relevant than the increase of organic matter and fine sediments so that the structure of infaunal assemblages became closer to a biologically controlled one (i.e., with higher species richness and abundance), gradually changing from shallow to deeper waters and from control to LCS affected areas.

In the UK structures (macrotidal shores) the influence of LCS was more localized (but, again, particularly concentrated on the landward side) and it was not possible to identify any consistent gradients in sediment characteristics or infaunal distribution at increasing distances from the structures. Although strengthened by the accumulation of seaweed detritus on the landward side, the effect around the LCS was low in Elmer, while the more dissipative beach at King's Parade (sand flat) and the design of the LCS, characterised by reduced porosity and a shore connection, contributed to deeper modifications (i.e. sediments much finer, muddier and anoxic) and the infauna was impoverished. Our results suggests that, contrary to what it may be expected in such a macrotidal regime, the potential impact of LCS is mainly determined by changes in the hydrodynamic conditions, sediment transport and detritus pathways rather than changes in tidal elevation.

\subsection{Forecasting impacts}

We have demonstrated the potential of biotope mapping and forecasting through modelling as a useful broad-brush tool in the early stages of design. Further refinement of the model is necessary both to increase its overall accuracy and to make sure that it is more generally applicable (i.e. its predictive ability is presently better under calm rather than stormy conditions). This project is ongoing and will enable the impacts of a structure to be estimated and possible layouts of sets of structures to be assessed in conjunction with physical modelling. This is, however, a rule-based model rather than a quantitative simulation model but it could be extremely valuable as a coarse tool in the early evaluation of different designs. Some qualitative predictions are possible using it. The presented application is indicative of the potential, but does not provide conclusive proof of the validity of the approach, due to the limitations posed by the available data for the case study at Elmer. Contradictory results for the reference situation indicate the sensitivity of the model to accurate quantification of 
physical parameters and the limitations of the empiric classification approach. Further testing of the approach to other cases is needed to provide proof of the validity of the approach.

\subsection{General predictions}

On exposed coarse sandy beaches on the Atlantic, English Channel, Irish Sea, North Sea coasts a fairly impoverished community dominated by amphipods, isopods and some polychaetes is likely to be modified by any LCS. The coarser the sediment and the steeper the beach, the less likely that any effect will be manifest. Dissipative beaches, like the sand flats on the Wirral, tend to be more strongly affected by the construction of LCS in the intertidal zone as the hydrodynamic conditions change more abruptly in proximity of the structures. On these extensive sand flats, which also have a good supply of fine suspended material from the Mersey estuary, LCS can lead to build up of very fine material to the landward side of the structures and thus a markedly different fauna. Such a build up of fine material also occur in the Adriatic, especially where groynes and riverine inputs lead to analogue to lagoons.

As a general rule the furthest away from the shoreline that the structure can be built (without compromising wave-breaking) the better for the biota of the area. In the Adriatic overtopping or porosity is very important to avoid water stagnation. As yet we have little information on the influence of arrangement and layout of structures on the degree of impact on the fauna. However the more the wave and water regimes are altered the greater the changes will be. LCS will increase the habitat level of diversity by changing uniform exposed, coarse sand assemblages to a localised mosaic of different types of assemblages. Deposit feeders will dominate the community as more organic matter is trapped. Secondary productivity is also likely to increase. Badly designed LCS deployed extensively (e.g. the Adriatic) are likely to cause extensive areas of stagnation and possible anoxic conditions. They should be avoided in areas rich in organic matter and fine sediments such as estuary mouths. On more open tidal coasts the impacts are likely to be less and diversity and production may increase.

The above conditions may also favour the accumulation of seaweed-detritus on the beaches. Piles of rotting detritus are perceived by humans as negative (e.g. nuisance for sunbathing and other activities in the beach and generation of bad smell and flies due to the natural decomposition of the detritus). It should be pointed out, however, that accumulation of wreck on beaches which have seagrass meadows in front (particularly those of Posidonia 
oceanica in the Mediterranean) may be helpful to protect the beach line against the erosion, particularly during the annual stormy periods (Boudouresque and Meinesz, 1982; Masuti Pascual et al., 2000).

When designing LCS, the use of the biotope predictive tool here developed appears to be very useful. The results of the initial trials with the model are highly encouraging. However, the model is still being refined in order to develop the tool for more accurately predicting change in the identity and extent of biotopes as a result of the addition of LCS. More specific details regarding the biotopes identified by the model as being affected by LCS structures can be found in Frost et al. (In prep.).

\subsection{Mobile fauna}

Studies of mobile fauna were approached by means of a balanced hierarchical sampling design, identical to that used for the soft bottoms. In the case of the mobile fauna, in general, our results showed that the LCS do not increase the overall diversity in the area. However, they create a substrate for the development of local assemblages that remain at early stages of succession. None of the species found around the artificial substrata are introduced compared to the local fauna from the nearby rocky bottoms. This suggests that LCS, especially when built in coastal areas dominated by soft-bottoms, can have a strong effect in the structure of fish community by attracting species typical of rocky shores therefore locally increasing diversity. The populations of the different species mainly consist, however, of juvenile stages and individuals usually no older than two years. Therefore, it appears that the LCS do not provide appropriate habitats for persistent adult fish populations, because of the small size of the structure, the usual absence of branched algae and the intense sport fishing activities around the structure.

Furthermore, our results also indicate that the local settlement of fish and crustaceans around the LCS may also be indirectly enhanced through the accumulation of drifting algae. This detritus appears to be an attractive habitat for new settlers of and juveniles of several species of mobile fauna, chiefly fish and crabs. Conversely, besides the effective role in protecting the shoreline (see above) once on the beach, the underwater accumulations of drifting seagrass leaves (mainly Posidonia oceanica) did not prove to attract mobile fauna, likely due their particular 3-dimensional structure, which was more compact than that of algal accumulations. 


\section{Implications for management}

LCS consistently impacts the sediments and faunal assemblages across all sites examined in the EU by disrupting their native progression from shoreline to deep waters. Independently of the arrangement of the structures, LCS usually induces substantial and predictable changes in the surrounding soft bottom communities, mainly in relation to the degree of hydrodynamism (i.e. increasing hydrodynamism on the landward side, decreasing hydrodynamism on the landward side). However, these changes are most evident on the landward side, particularly in the presence of additional structures (such as parallel groins) or after beach nourishment.

The consequences of LCS construction always depend on the response of the particular assemblages inhabiting a given soft-bottom area. Thus, it is important to know the composition of these assemblages before the construction, in order to be able to assess likely changes (e.g. species disappearance-from and/or colonization-of the new environment). Despite the differences observed around the LCS, however, the overall habitat diversity of the stretch of coast where the structures are built usually tends to increase and, as a consequence, the species diversity also tends to increase. The induced changes may be deemed desirable or undesirable by humans. For instance, the increase in biodiversity is a modification of background conditions that may be perceived as a negative ecological impact. In turn, an enhancement of the value of a fish nursery ground of a particular stretch of coast appears as a positive impact from recreational or commercial fisheries perspective.

In order to assess the ecological importance of the induced changes, special attention must be given to the individual species responsible for the changes in assemblage diversity. As a result of the presence of LCS, species present under natural conditions might disappear but, at the same time, the new conditions appear thus allowing different species to colonise the new type of habitat. Whether these changes are caused by accidental species coming from the newly added hard bottoms or from species associated with less physical disturbances (e.g., organic enrichment, siltation, presence of stagnant or brackish waters), the increase in softbottom infaunal biodiversity must be considered as a negative transformation of the environment. The possible presence of indicator species should be taken into account in order to provide additional monitoring criteria. The combined use of basic monitoring approaches and models allowing to forecast likely impacts on the surrounding biotopes (such as the model developed by Delft Hydraulics/MBA within DELOS) will certainly allow 
identification of impacts of the LCS, as well as play a relevant role in the mitigation of the possible impacts .

Our work supports the feasibility of introducing design criteria tending to facilitate a positive evolution of the faunal assemblages surrounding the structures once the changes due to the presence of the LCS are completed and the new situation tends to become more stable. In general, these criteria must be addressed to avoid the development of insalubrious areas in the protected zone (i.e. on the landward side). For instance, by keeping the modifications of both the onshore wave transport and water flow to the minimum necessary. Possible interventions are: maximise the overtopping and the porosity of structure, maximise the gap size and their frequency within each LCS, minimise the structure length and number, avoid beach nourishment (specially if planned to be carried out in successive periods) and minimise the enclosure of the protected zone (avoiding lateral groynes if at all possible).

The European Community Biodiversity Strategy developed in the communication (98)42, aims to anticipate, prevent and attack the causes of significant reduction or loss of biodiversity at the source, helping both to reverse present trends in biodiversity reduction or losses and to place species and ecosystems at a satisfactory conservation status, both within and beyond the territory of the European Community. This strictly agrees with the United Nations' Convention on Biological Diversity. The principle is, thus, to maintain the most natural ecosystem conditions, and to protect them from human intervention.

In conclusion, the effects of LCS should always be minimised, the number of LCS should be reduced to the minimum necessary to protect the coast, avoiding large-scale effects of habitat loss, fragmentation and community changes.

\section{Acknowledgements}

The authors are indebted to the European Community for funding, through the 5th Framework Programme, the DELOS project (Contract: $n^{\circ}$ EVK3-CT-2000-00041) within which this research has been carried out. Special thanks also to the DELOS co-ordinator Dr. A. Lamberti and the leader of the Ecology Task, Dr. P. Aalberg and to the Southampton Oceanography Centre, and to Dr. M Collins in particular, who provided the environmental inputs required to run the biotope modelling at the Elmer case study site. Thanks also to Javier Macpherson, who made the drawings of the aerial views of the study sites. 


\section{References}

Begon, M., Harper, J.L. and Townsend, C.R. 1996. Ecology. Individuals, Populations and Communities. Ed. Blackwell Science, Oxford.

Boudouresque, C.F. and Meinesz, A. 1982. Découverte de l'herbier de posidonie. Cahiers du Parc National de Port Cross, 4, pp. 1-80.

Brazeiro, A. 2001. Relationship between species richness and morphodynamics in sandy beaches: what are the underlying factors? Mar. Ecol.Prog. Ser., 224, pp. 35-44.

Butman, B. 1987a. The effect of winter storms on the bottom. In: Backus, R.H. (ed.), Georges Bank. MIT Press, Cambridge. pp. 74-77.

Butman, B. 1987b. Physical processes causing superficial-sediment movement. In: Backus, R.H. (ed.), Georges Bank. MIT Press, Cambridge. pp. 147-162.

Chatfield, C., Collins, A.J. 1980. Introduction to multivariate analysis. Chapman and Hall, London.

Clarke, K.R. 1993. Non-parametric multivariate analyses of changes in assemblage structure. Aust.J. Ecol., 18, pp. 117-143.

Clarke, K.R. and Gorley, R.N. 2001. PRIMER v5: user manual/tutorial (Plymouth routines in multivariate ecological research). Ed. Primer Ltd., Plymouth. 91 pp.

Clarke, K.R. and Warwick, R.M. 1994. Change in marine community: An approach to statistical analysis and interpretation. Ed. Plymouth Marine Laboratory, Plymouth.

Connor, D.W., Allen, J.H., Golding, N., Lieberknecht, L.M., Northen, K.O. and Reker, J.B. 2003. The National Marine Habitat Classification for Britain and Ireland. Version 03.02. http://www.jncc.gov.uk/marine/biotopes. Joint Nature Conservation Committee, Peterborough.

Dauvin, J.C. and Ibanez, F. 1986. Variations à long-terme (1977-1985) du peuplement des sables fins de la Pierre Noire (Baie de Morlaix, Manche Occidentale): analyse statistique de l'évolution structurale. Hydrobiologia, 142, pp. 171-186.

Duffy-Anderson, J.T., Manderson, J.P. and Able, K.W. 2003. A characterization of juvenile fish assemblages around man-made structures in the New York New Jersey Harbor Estuary, USA. Bull. Mar. Sci., 72, pp. 877-889.

Fauchald, K. and Jumars, P.A. 1979. The diet of worms: A study of polychaete feeding guilds. Oceanogr. Mar. Biol. Ann. Rev., 17, pp. 193-284.

Grassle, J.P. and Grassle, J.F. 1976. Sibling species in the marine pollution indicator Capitella (Polychaeta). Science, 192, pp. 567-569. 
Gray, J.S. 1981. The ecology of marine sediments. An introduction to the structure and function of benthic communities. First Ed. Cambridge University Press, Cambridge. 185 pp.

Heatwole, H. and Levins, R. 1972. Trophic structure stability and faunal changes during recolonization. Ecology, 53, pp. 531-534.

Holm-Hansen, O. and Riemann, B. 1978. Chlorophyll- $a$ determination improvements in methodology. Oikos, 30, pp. 438-447.

Holme, N.A. and McIntyre, A.D. 1971. Methods for the study of marine benthos. Eds. Blackwell, Oxford, U.K. 334 pp.

Jumars, P.A. and Nowell, A.R.M. 1984. Effects of benthos on sediment transport: difficulties with functional grouping. Cont. Shelf Res., 3, pp. 115-130.

Lesser, G.R. 2000. Computation of three-dimensional suspended sediment transport within the DELFT3D-FLOW module. MSc thesis, IHE, Delft.

Lesser, G.R., Kester, J.v, Roelvink, J.A. and Stelling, G.S.,2002.- Development and validation of a three-dimensional morphological model.

Levinton, J.S. 1991. Variable feeding behaviour in three species of Macoma (Bivalvia: Tellinidae) as a response to water flow and sediment transport. Mar. Biol., 110, pp. 375383.

Lorenzen, C.J. 1967. Determination of chlorophyll and pheo-pigments: spectrophometric equations. Limnol. Oceanogr., 12, pp. 343-346.

Martin, D., Ballesteros, E., Gili, J.M. and Palacín, C. 1993. Small-scale structure of infaunal polychaete communities in an estuarine environment: Methodological approach. Estuar. Coast. Shelf Sci., 36, pp. 47-58.

Martin, D., Pinedo, S. and Sardá, R. 2000. Distribution patterns and trophic structure of softbottom Polychaete assemblages in a North-Western Mediterranean shallow-water Bay. Ophelia, 53, pp. 1-17.

Masuti Pascual, E., Grau Jofre, A.M., Duarte, C.M., Terrados, J. and Marbà, N. 2000. La Posidònia: l'alga que no ho és. Quaderns de Pesca, 5, pp. 1-59.

McArdle, S.B. and McLachlan, A. 1992. Sand beach ecology: swash features relevant to the macrofauna. J. Coast. Res., 8, pp. 398-407.

McLachlan, A., Jaramillo, E., Defeo, O., Dugan, , De Ruyck, A. and Coetzee, P. 1995. Adaptations of bivalves to different beach types. J. Exp. Mar. Biol. Ecol., 187, pp. 147160. 
Miller, D.C. and Sternberg, R.W. 1988. Field measurements of the fluid and sedimentdynamic environment of a benthic deposit feeder. J. Mar. Res., 46, pp. 771-796.

Nowell, A.R.M. 1983. The benthic boundary layer and sediment transport. Rev. Geoph. Space Phys., 21, pp. 1181-1192.

Nowell, A.R.M. and Jumars, P.A. 1984. Flow environments of aquatic benthos. Ann. Rev. Ecol. Syst., 15, pp. 303-328.

Paiva, P.C. 1993. Trophic structure of a shelf polychaete taxocoenosis in southern Brazil. Cah. Biol. Mar., 35, pp. 39-55.

Paiva, P.C. 2001. Spatial and temporal variation of a nearshore benthic community in Southern Brazil: Implications for the Design of Monitoring Programs. Estuar. Coast. Shelf Sci., 52, pp. 423-433.

Pearson, T.H. and Rosenberg, R. 1978. Macrobenthic succession in relation to organic enrichment and pollution in marine environment. Oceanogr. Mar. Biol. Ann. Rev., 16, pp. 229-311.

Pinedo, S., Sardá, R. and Martin, D. 1997. Comparative study of the trophic structure of the soft bottom assemblages in the Bay of Blanes (Western Mediterranean Sea). Bull. Mar. Sci., 60, pp. 529-543.

Pocklington, P. and Wells, P.G. 1992. Polychaetes. Key taxa for marine environmental quality monitoring. Mar. Poll. Bull., 24, pp. 593-598.

Probert, P.K. 1984. Disturbance, sediment stability, and trophic structure of soft-bottom communities. J. Mar. Res., 42, pp. 893-921.

Rosenberg, R. 1995. Benthic marine fauna structured by hydrodynamic processes and food availability. Neth. J. Sea Res., 34, pp. 303-317.

Sanchez-Jerez, P., Gillanders, B.M., Rodriguez-Ruiz, S. and Ramos-Esplá, A. 2002. Effect of an artificial reef in Posidonia meadows on fish assemblage and diet of Diplodus annularis. ICES. J. Mar. Sci., 59 Suppl., pp. 59-68.

Sanders, H.L. 1969. Benthic marine diversity and the stability-time hypothesis. Brookhaven Symp. Biol., 22, pp. 71-80.

Shannon, C.E. and Weaver, W. 1949. The mathematical theory of communication. Ed. Illinois University Press, Urbana. 117 pp.

Short, A.D. and Wright, L.D. 1983. Physical variability of sandy beaches. In: McLachlan, A. and Erasmus, T. (eds.), Sandy beaches as ecosystems. Junk, W., The Hague. pp. 133-144.

Snelgrove, P.V.R. and Butman, C.A. 1994. Animal-sediment relationships revisited: Cause versus effect. Oceanogr. Mar. Biol. Ann. Rev., 32, pp. 111-177. 
Taghon, G.L. and Greene, R.R. 1992. Utilization of deposited and suspended particulate matter by benthic "interface” feeders. Limnol. Oceanogr., 37, pp. 1370-1391.

Taghon, G.L., Nowell, A.R.M. and Jumars, P.A. 1980. Induction of suspension feeding in spionid polychaetes by high particulate fluxes. Science, 210, pp. 562-564.

Underwood, A.J. 1997. Experiments in Ecology. Their logical design and interpretation using analysis of variance. Ed. Cambridge University Press, Cambridge, United Kingdom.

Underwood, A.J. and Jernakoff, P. 1981. Effects of interactions between algae and grazing gastropods on the structure of a low-shore intertidal algal community. Oecologia, 28, pp. 221-233.

Wentworth, W. 1972. A scale of grade and class terms for clastic sediments. J. Geology, 30, pp. 377-392. 


\section{TABLES}

Table 1. - Results from nested ANOVA's a the 5 study sites based on sediment descriptors. Chl-a: Chlorophyll-a; TOM: total organic matter; T: treatment; NS: non-significant; * $\mathrm{p}<$ $0.05 ; * * \mathrm{p}<0.001 ; * * * \mathrm{p}<0.0001$.

\begin{tabular}{lcccccc}
\hline & Chl-a & \multicolumn{3}{c}{ Silt/clay $(\%)$} \\
\cline { 2 - 7 } & Treatment & Site (T) & Treatment & Site (T) & Treatment & Site (T) \\
\hline Cubelles & NS & $* * *$ & NS & $*$ & NS & $* *$ \\
Altafulla & NS & $* *$ & NS & NS & NS & $* * *$ \\
Elmer & NS & $* *$ & NS & $*$ & NS & $* * *$ \\
King's Parade & $* *$ & NS & NS & $* * *$ & $* *$ & $* *$ \\
Lido di Dante & NS & NS & NS & $* * *$ & NS & $* * *$ \\
\hline
\end{tabular}

Table 2. - Results from nested ANOVA ANOVA's a the 5 study sites based on infaunal community descriptors. NoS: Number of species; Shannon: Shannon diversity index; T: treatment; NS: non-significant; $* \mathrm{p}<0.05 ; * * \mathrm{p}<0.001 ; * * * \mathrm{p}<0.0001$.

\begin{tabular}{lllll}
\hline & \multicolumn{2}{c}{ NoS } & Shannon & \\
\cline { 2 - 5 } & Treatment & Site $(\mathrm{T})$ & Treatment & Site $(\mathrm{T})$ \\
\hline Cubelles & NS & $* *$ & NS & NS \\
Altafulla & $*$ & $* * *$ & NS & $* * *$ \\
Elmer & NS & $* * *$ & NS & $* * *$ \\
King's Parade & NS & $* * *$ & $* *$ & $* * *$ \\
Lido di Dante & $* *$ & $* * *$ & $* * *$ & \\
\hline
\end{tabular}

Table 3. - Results from nested ANOSIM ANOVA's at the 5 study sites based on the infaunal species per sample matrix. T: treatment; C: control; L: landward; S: seaward; NS: nonsignificant; $* \mathrm{p}<0.05 ; * * \mathrm{p}<0.001$

\begin{tabular}{llllll} 
& & & \multicolumn{2}{c}{ Pairwise comparison } \\
\cline { 3 - 5 } & Treatment & Site $(\mathrm{T})$ & C vs. S & C vs. L & S vs. L \\
\hline Cubelles & $*$ & $*$ & $*$ & $*$ & $*$ \\
Altafulla & $* *$ & $* *$ & $*$ & $*$ & $*$ \\
Elmer & $* *$ & $* *$ & NS & $*$ & $*$ \\
King's Parade & $*$ & $* *$ & NS & $*$ & $*$ \\
Lido di Dante & $*$ & $* *$ & NS & $*$ & $*$ \\
\hline
\end{tabular}



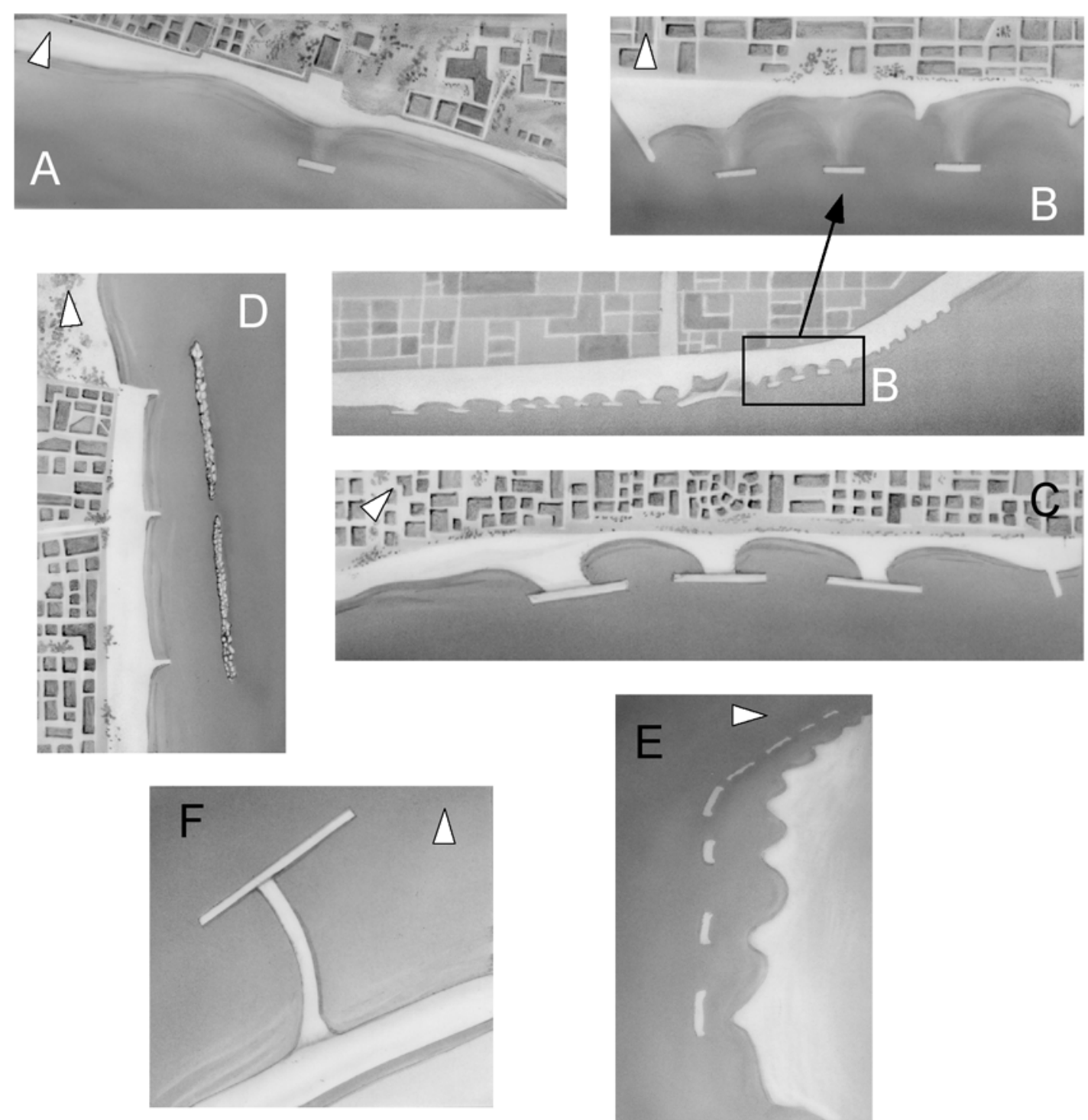

Figure 1.- Aerial images of the studied LCS systems. A. Altafulla. B. Cubelles. C. Calonge. D. Lido di Dante. E. Elmer. F. King's Parade (only the T-shaped LCS). White arrow are pointing to the North. 

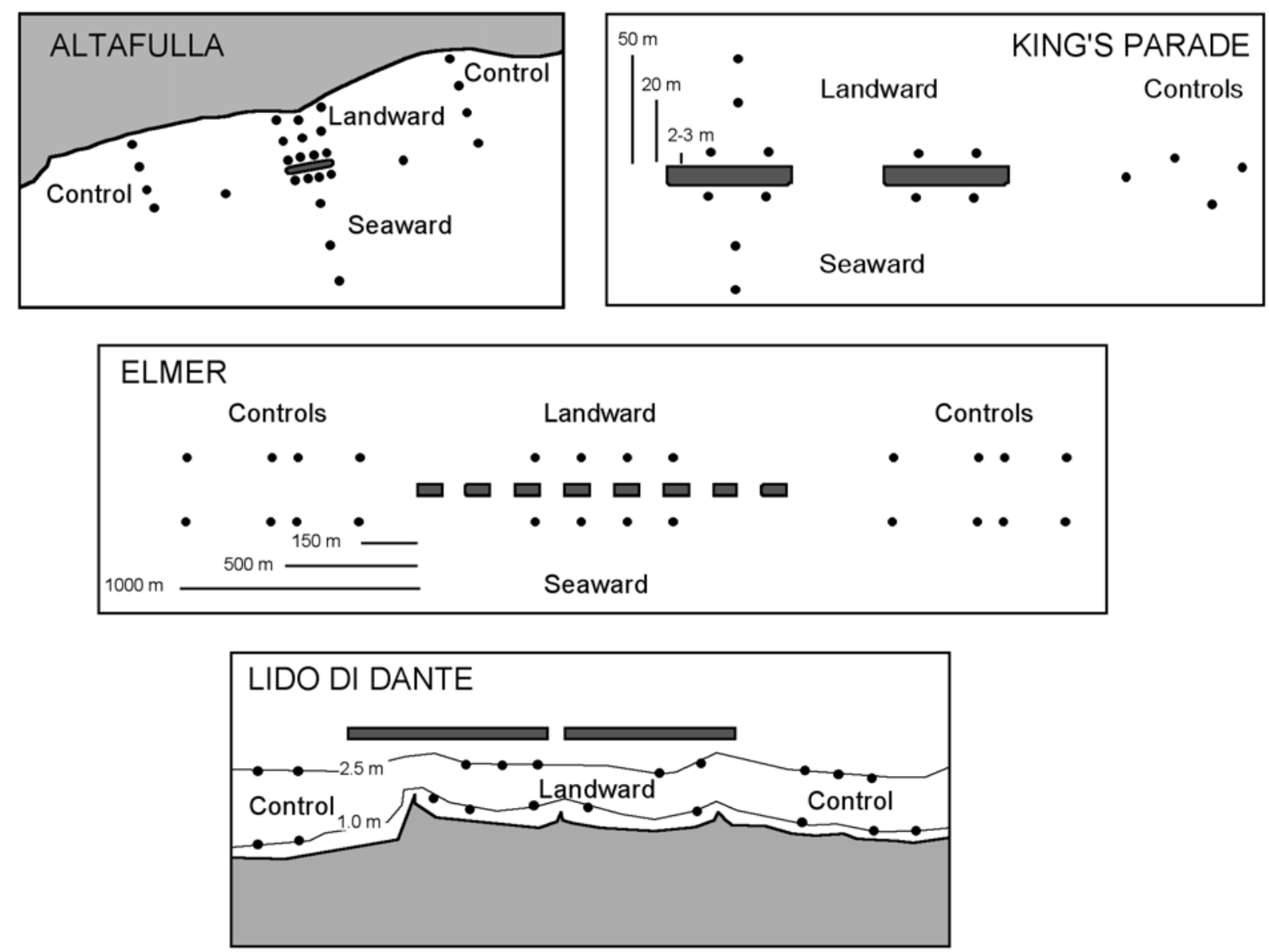

Figure 2.- Schemes of the sampling strategies to assess the extent of the area of influence of the LCS at successive distances from the structures designed at the five different study sites.

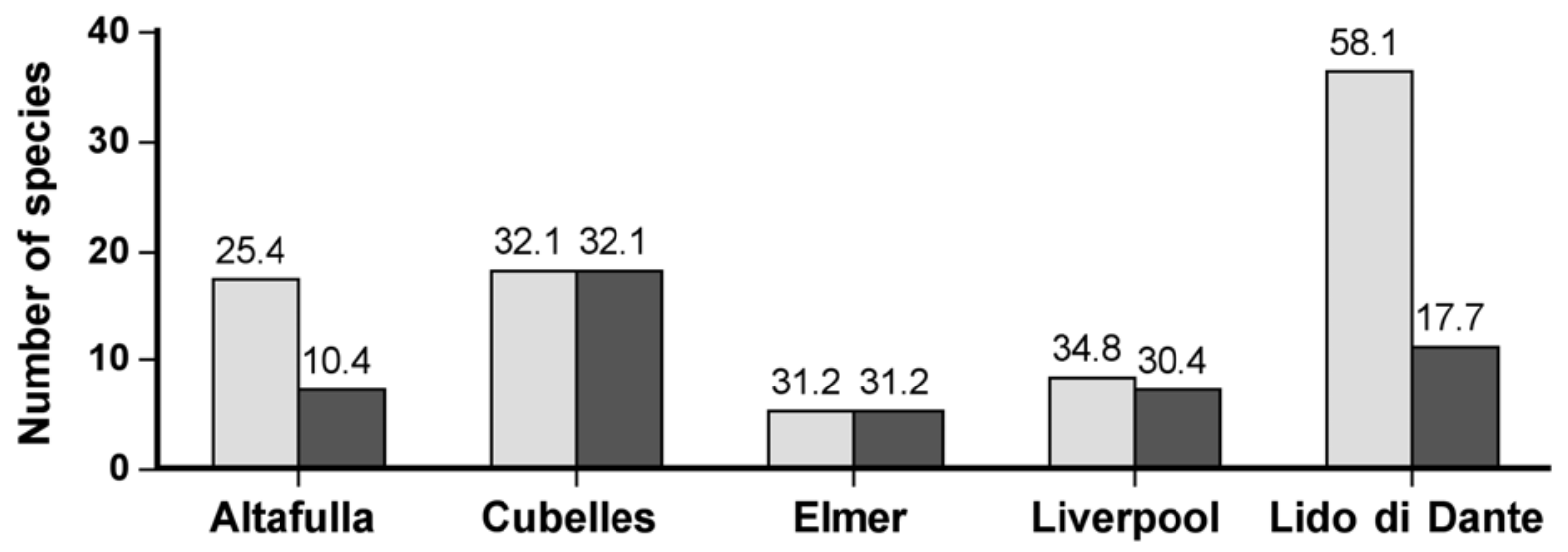

\section{Landward $\square$ Seaward}

Figure 3.- Number of exclusive species (i.e. found either on the landward side or on the landward side and not in the controls). Bar labels indicate the percentages relative to controls. 

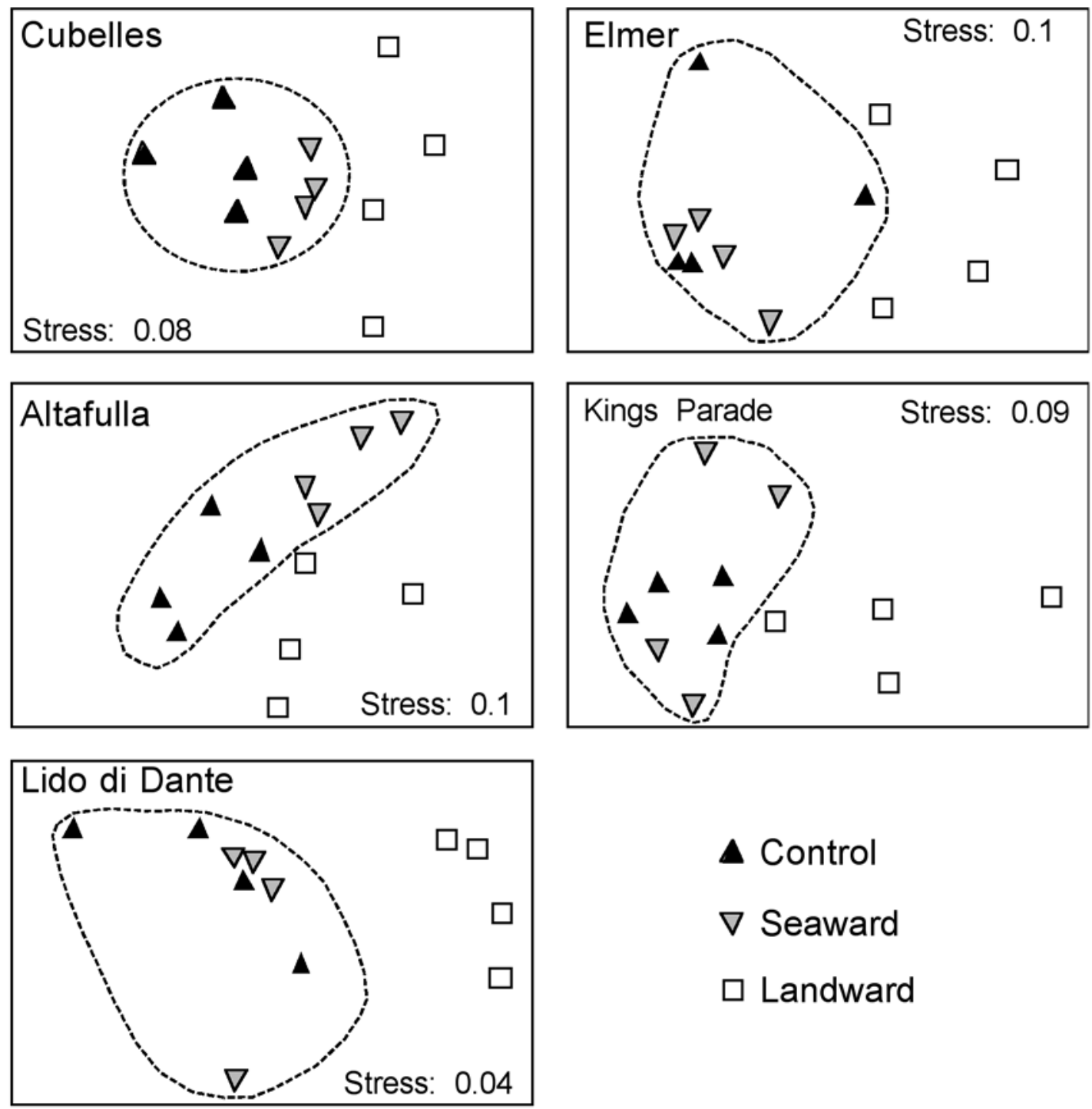

$\Delta$ Control

$\nabla$ Seaward

Landward

Figure 4.- Non-metric MDS analyses of the macrofauna based on the ANOVA design at the five study sites. Dotted line outline the seaward/control clusters. 

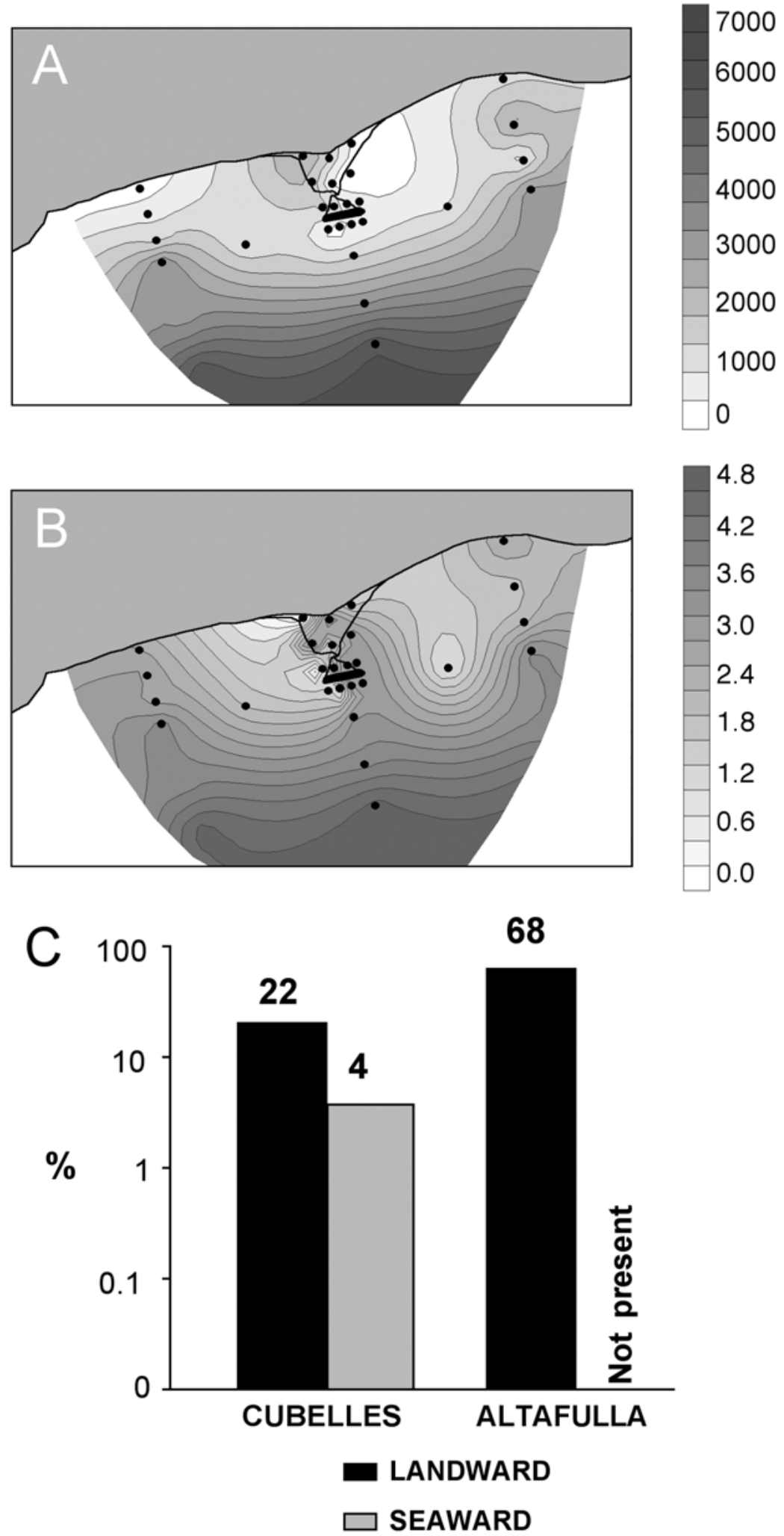

Figure 5.- A. Changes in the percentage of fine sediments at successive distances from the Altafulla LCS. B. Changes in infaunal abundance (individuals per $\mathrm{m}^{-2}$ ) at successive distances from the Altafulla LCS. C. Response of the indicator species Capitella capitata to the presence of the LCS in Cubelles and Altafulla, expressed as the relative percentage (in abundance) with respect to the controls. 


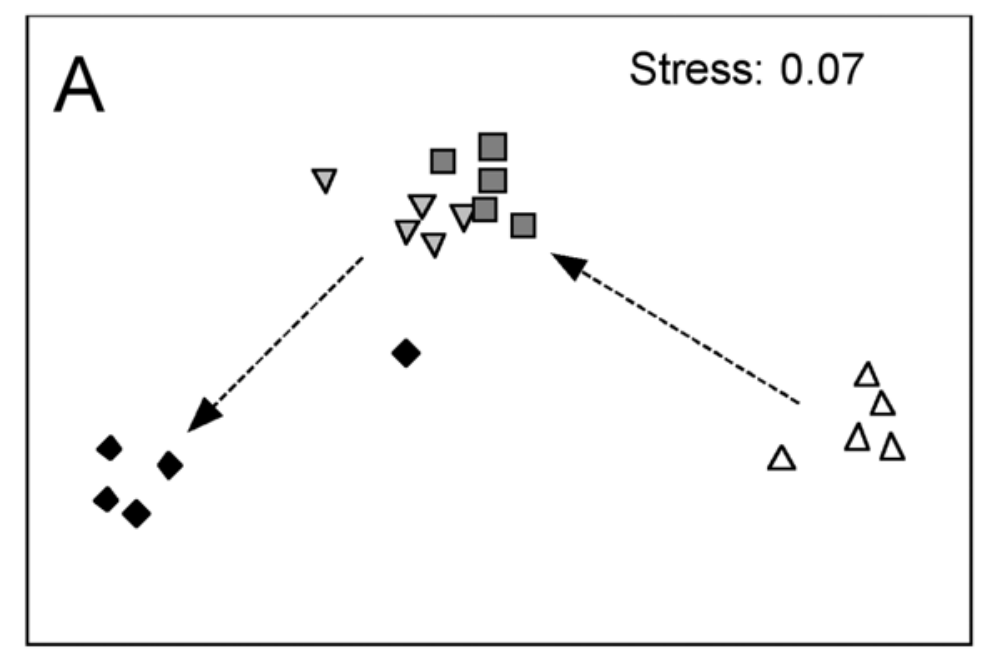

\begin{tabular}{|lcc|}
\hline & $1 \mathrm{~m}$ & $2.5 \mathrm{~m}$ \\
Control & $\Delta$ & $\nabla$ \\
Landward & $\square$ & $\bullet$ \\
\hline
\end{tabular}
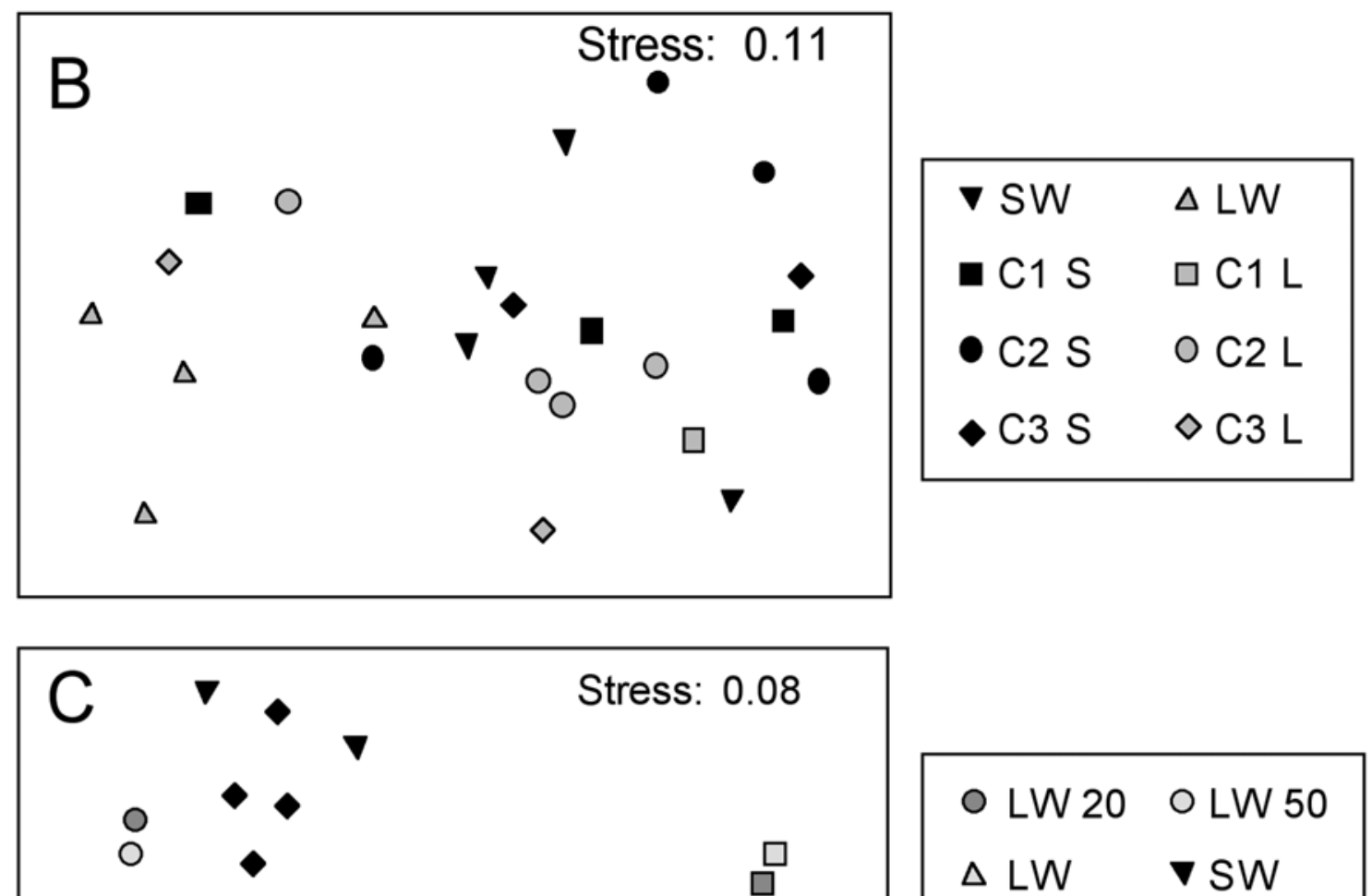

Stress: 0.08

$\Delta$

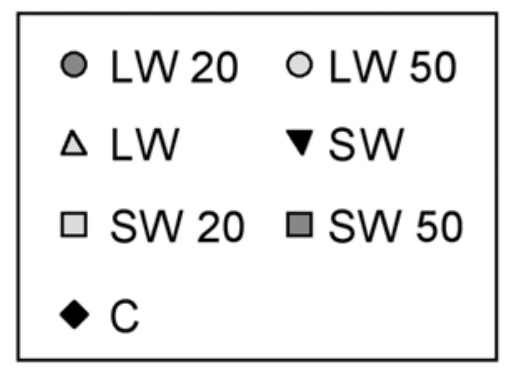

$\Delta$

Figure 6.- Non-metric MDS based on macroinfaunal abundances. A. Lido di Dante, with arrows outlining the changes from exposed to sheltered conditions. B. Elmer (West Sussex). C. King's Parade (Wirral). SW: seaward, LW: landward; C1 t C3: control sites at $150 \mathrm{~m}, 500 \mathrm{~m}$ and $1000 \mathrm{~m}$ from Elmer structure, respectively; S and L: controls at the same tidal level as seaward and landward sides of the Elmer structures, respectively; C: control at King's Parade L20 - L50, S20 - S50: sites at $20 \mathrm{~m}$ and $50 \mathrm{~m}$, inshore and offshore from King's Parade structure, respectively. Points represent sampling sites at Lido di Dante and the average for each area at Elmer and Kings Parade. 

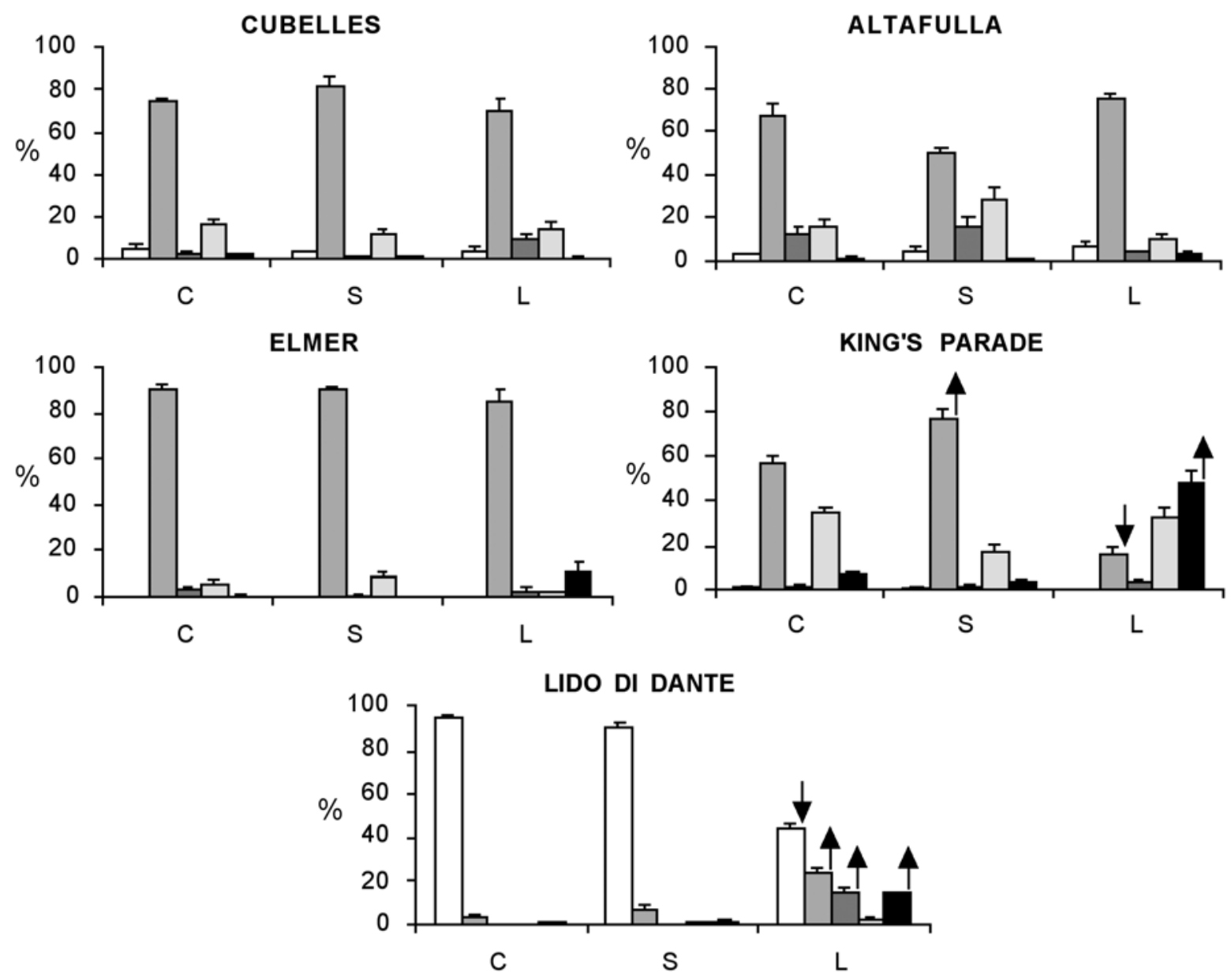

Suspension feeders

Carnivores / omnivores

Mixed feeders

$\square$ Surface deposit feeders

Sub-surface deposit feeders

Figure 7. Percent composition of trophic groups in the treatment sites of the studied localities. C: control; S: seaward; L: landward. Upward and downward arrows indicates significant increase or decrease with respect to the control values, respectively. For trophic groups identifications see legend. 

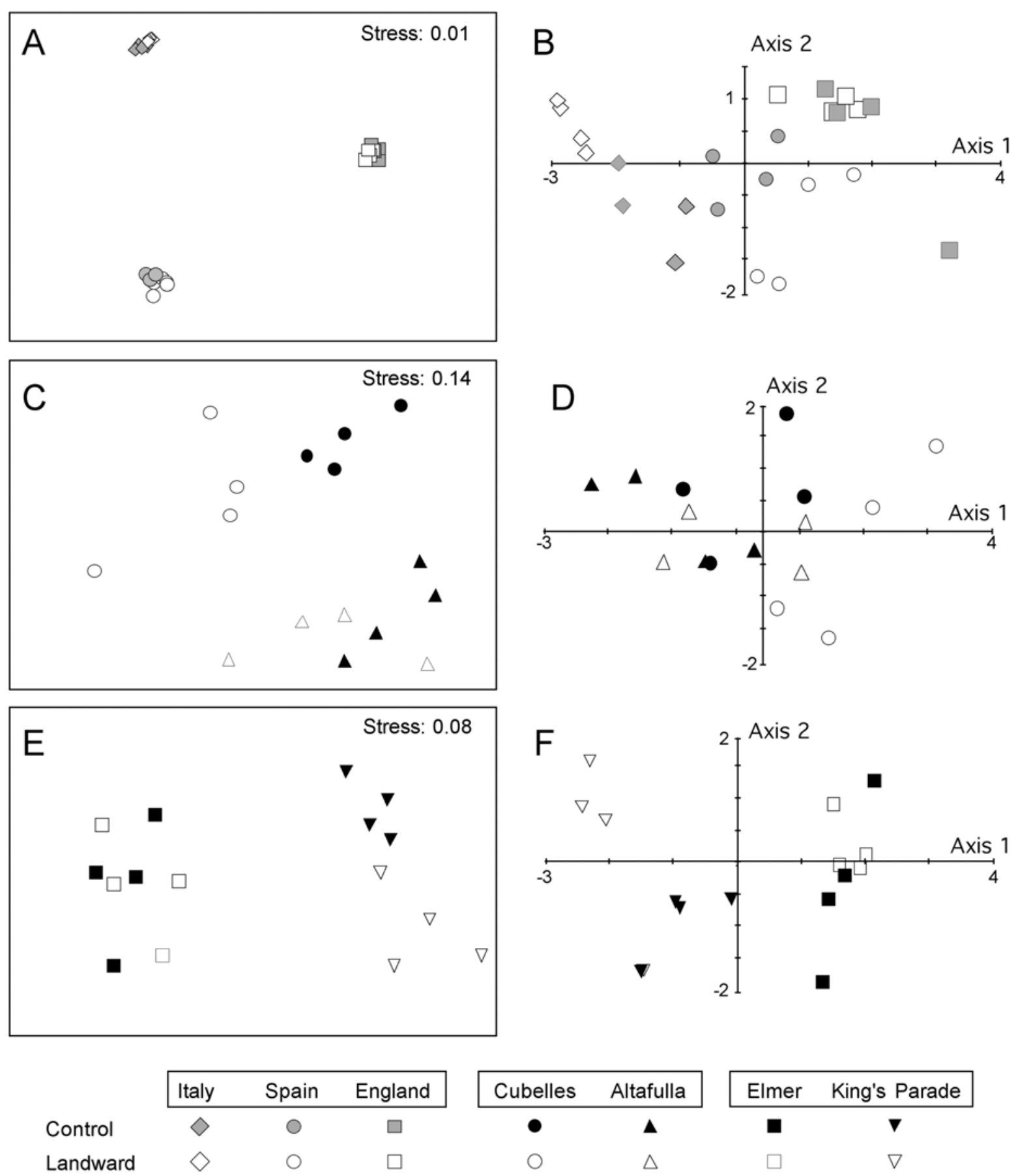

Figure 8.- A. Non-metric MDS based on log-transformed abundances of macrofauna; B. PCA plot based on logtransformed trophic groups abundances. C. Non-metric MDS based on log-transformed abundances of macrofauna; D. PCA plot based on log-transformed trophic groups abundances. E. Non-metric MDS based on log-transformed abundances of macrofauna; F. PCA plot based on log-transformed trophic groups abundances. See text for axis explanations. Points represent sampling sites. 

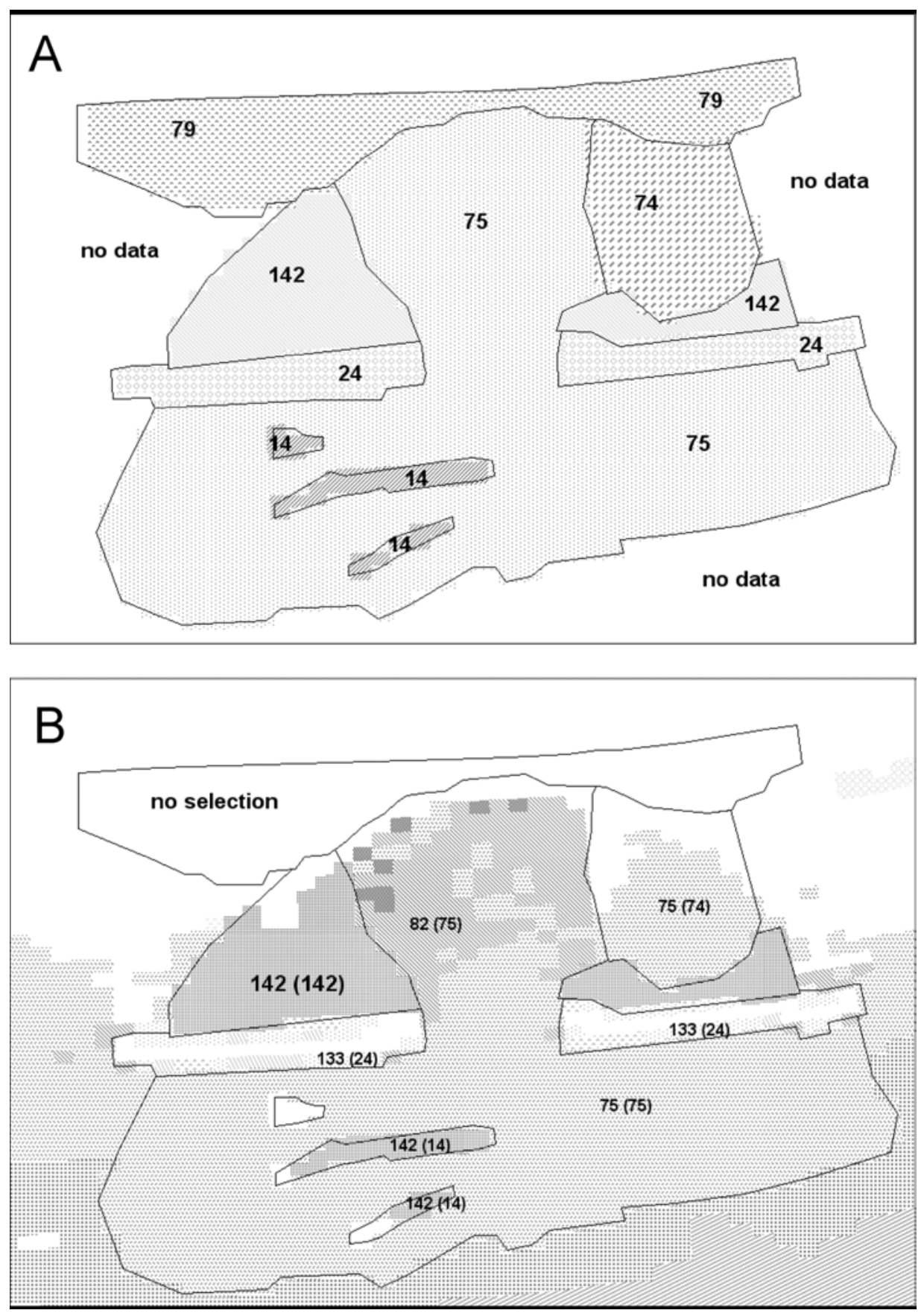

Figure 9.- A. Identity and location of biotopes at Elmer as observed from fieldwork observations and samples. Each polygon mapped has been designated a BioMar biotope code and an arbitrarily assigned biotope number: 14 (LR.Rkp.H) = Hydroids, ephemeral seaweeds and Littorina littorea in shallow eulittoral mixed substrata pools; 24 (ELR.MB.Bpat) = Barnacles and Patella spp. on exposed or moderately exposed, or vertical sheltered, eulittoral rock; 74 (LGS.S.Aeur) = Burrowing amphipods and Eurydice pulchra in well drained clean sand shores; 75 (LGS.S.AP) = Burrowing amphipods and polychaetes (often Arenicola marina) in clean sand shores; 79 (LGS.Sh.BarSh) = Barren Littoral Shingle (not used for model comparison); 142 (SLR.Fx.Ephx) = Ephemeral green and red seaweeds on variable salinity or disturbed eulittoral mixed substrata. B. Map showing comparison of field biotopes with biotopes predicted by the model. Biotopes selected by the model are shown first followed by field biotopes in parenthesis. Additional biotopes selected by the model but not recorded for the real situation: 82 = Macoma balthica and Arenicola Marina in muddy sand shores; $133=$ Ascophyllum nodosum on very sheltered mid-eulittoral rock; $141=$ Barnacles and Littorina littorea on unstable eulittoral mixed substrata. 'No selection' is output where the model has not been able to find any potential biotope for the range of parameters selected. 

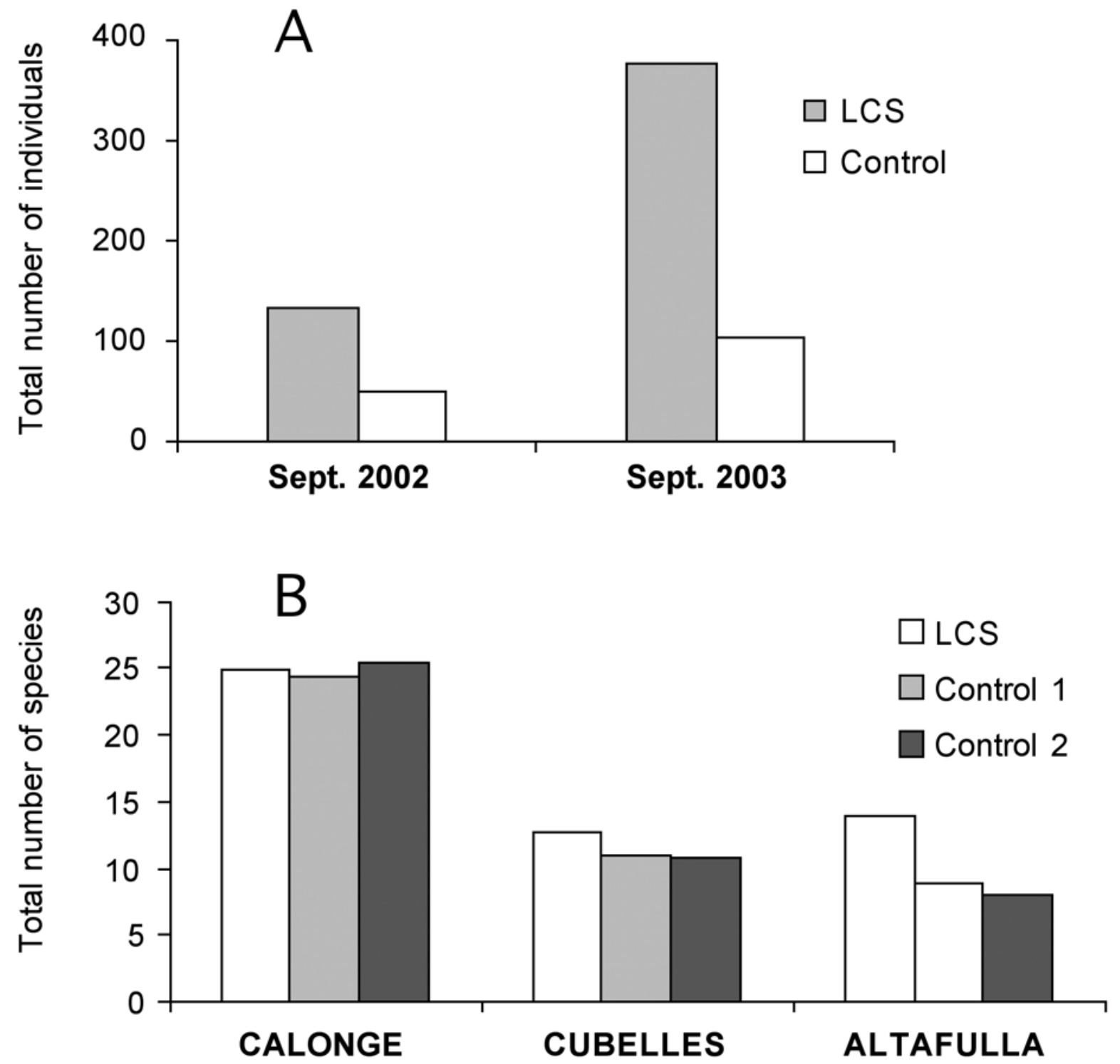

Figure 10.- A. Total number of juvenile sea bass (Dicentrarchus labrax) caught around the LCS structures (seaward and landward) and in control sites at Elmer during the DELOS fish surveys in 2001 and 2002 (Only individuals less than $10 \mathrm{~cm}$ long were considered). B. Number of fish species in the communities around the Spanish LCS. 